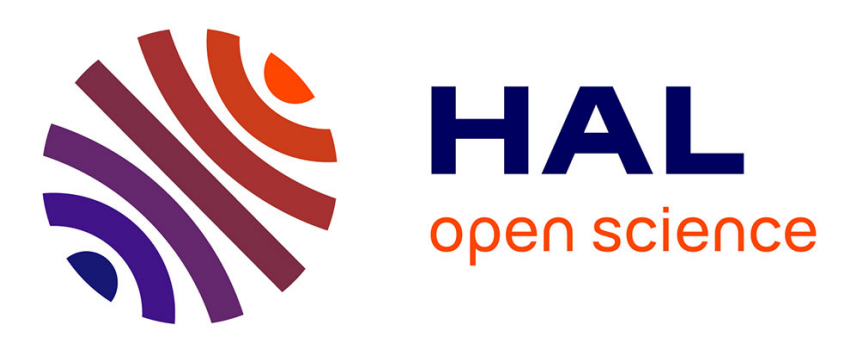

\title{
Integration of a Flat Holonic Form in an HLA Environment
}

Fouzia Ounnar, Patrick Pujo, Lynda Mekaouche, Norbert Giambiasi

\section{To cite this version:}

Fouzia Ounnar, Patrick Pujo, Lynda Mekaouche, Norbert Giambiasi. Integration of a Flat Holonic Form in an HLA Environment. Journal of Intelligent Manufacturing, 2009, 20 (1), pp.91-111. 10.1007/s10845-008-0106-4 . hal-01212613

\section{HAL Id: hal-01212613 https://hal.science/hal-01212613}

Submitted on 21 Oct 2015

HAL is a multi-disciplinary open access archive for the deposit and dissemination of scientific research documents, whether they are published or not. The documents may come from teaching and research institutions in France or abroad, or from public or private research centers.
L'archive ouverte pluridisciplinaire HAL, est destinée au dépôt et à la diffusion de documents scientifiques de niveau recherche, publiés ou non, émanant des établissements d'enseignement et de recherche français ou étrangers, des laboratoires publics ou privés. 


\title{
Integration of a Flat Holonic Form in an HLA Environment
}

\author{
Fouzia Ounnar ${ }^{1}$, Patrick Pujo, Lynda Mekaouche, Norbert Giambiasi \\ Laboratoire des Sciences de l'Information et des Systèmes (LSIS) \\ UMR - CNRS 6168 \\ Université Paul Cézanne \\ Avenue Escadrille Normandie Niemen \\ 13397 Marseille Cedex 20 - France \\ Phone: (33) 0491056010 \\ Fax: (33) 0491056033 \\ E-mail: \{fouzia.ounnar, patrick.pujo, lynda.mekaouche, norbert.giambiasi\}@1sis.org
}

\begin{abstract}
Managers need to create and sustain internal systems and controls to ensure that their customer focused strategies are being implemented. Companies are currently in a spiral of permanent optimization. Accordingly, many companies turn to their core activity. In this framework, one notices the development of the concept of "industrial partnership". In this context and to control the Customer-Supplier Relationships (CSR), we proposed a selforganized control model in which all partner entities (Customers/Suppliers) negotiate to guarantee good quality connections between customers and suppliers. This means meeting customer expectations as closely as possible and respecting supplier capacities. In this proposal, self-organized control is characterized more precisely by an organizational architecture of the flat holonic form type. This flat holonic form is based on the concept of Autonomous Control Entity (ACE). The holonic architecture, the behaviour of an ACE, the interaction mechanisms between ACEs and the self-evaluation supplier process are presented, and then the modelling of ACEs using DEVS (Discrete EVent system Specification) is described. An implementation of the simulation of such a system was done via a distributed simulation environment HLA (High Level Architecture). A case study illustrating the proposed approach is presented.
\end{abstract}

Keywords: Self-organized Control, Discrete EVent system Specification (DEVS), High Level Architecture (HLA), Flat Holonic Form, Autonomous Control Entity (ACE), Analytic Hierarchy Process (AHP).

\footnotetext{
${ }^{1}$ Corresponding author
} 


\section{INTRODUCTION}

In recent years, we have witnessed a strong evolution of the Customer-Supplier Relationships in order to obtain a better internal management of individual companies and a better global performance in meeting the requirements of their customers companies.

Indeed, the development of the concept of "industrial partnership" can be noticed. In this context and with the aim of controlling the Customer-Supplier Relationship (CSR), (Ounnar and Pujo, 2001) (Ounnar and Pujo, 2005) have proposed a self-organized control model, where the partnership is defined as the association in network of potential suppliers, which must collectively insure the distribution of the orders coming from the various customers companies. The control of relationships among partner companies involves all the actions they develop together to achieve their common objectives and to react in time to any failure of one of the partners. A negotiation among partners is thus required involving the management and organization of each partner's production. The proposed approach considers that all partner entities (Customers/Suppliers) negotiate to meet customer needs as well as possible and respect the suppliers' capacities. In other words, each potential supplier answers a Call For Proposals (CFP) launched by the customer on the network.

Such operations are proposed by the scientific community concerned with the holonic manufacturing (Deen, 2003). In our proposal, the self-organized control is characterized more precisely by an organizational architecture of the flat holonic form type (Bongaerts et al., 2000). Our approach is described with the support of the reference architecture PROSA ${ }^{2}$ (Van Brussels et al., 1998) which allows holonic approaches to be specified according to a breakdown into holons like "Product", "Resource", "Order" and "Staff". In our case, each company involved in a logistic chain becomes a Resource Holon when it is associated with a

\footnotetext{
${ }^{2}$ Product Resource Order Staff Architecture
} 
decision making entity providing the capability to interact with other companies. All the Resource Holons constitute a network of logistic partnership encompassing the concerned companies. The decision making entity is called ACE, standing for Autonomous Control Entity.

Each ACE was modelled under the DEVS formalism (Discrete EVent system Specification) (Mekaouche et al., 2005a). In order to validate the proposed approach, it was necessary to validate the global model of a partnership network. The emergence of the best supplier must be simulated on various workstations and must be integrable in a global simulation which will represent a set of tasks connected into a distributed simulation. In order to allow the network partners to respect their data confidentiality, we used a distributed simulation. For that reason, we integrated the DEVS models of an ACE into a distributed simulation HLA (High Level Architecture) environment.

After a literature review, the holonic architecture, as well as the descriptions of an ACE and the self-evaluation supplier process, will be presented. Then, the DEVS models allowing us to obtain the behaviour of an ACE and and to integrate these models in the HLA environment will be described. In order to compare the operation of an enterprise network in the context of static logistics chains ${ }^{3}$ control and in the context of dynamic logistics chains self-organized control, we will present the case study as well as the analysis of the results.

\section{LITERATURE REVIEW}

Industry globalization, the evolution of customer requirements and the appearance of complex products, have made companies realize that internal improvement and external competitive environment improvement are important but not sufficient. This has pushed researchers to go further and prove that integrating companies into a network is essential. In other words, the

\footnotetext{
${ }^{3}$ The control of static supply chains indicates that all the network supply chains are fixed. This approach is based on a precise commercial contract with commitments over volumes and periods.
} 
development of a company does not depend only on the improvement of its internal performance but requires the use of external resources (Brito and Roseira, 2004; Cousins and Spekman, 2003; Faems et al., 2005; Pradosh et al., 2005). This has made companies use outsourcing to produce complex products. Through outsourcing, companies tend to gather to perform in a joint project, thus forming a supply chain network seeking to optimize customer satisfaction. In order to answer the objectives of companies involved in a network, research was focused both on network modelling and on the methodologies allowing this type of network to be modelled (Chen et al., 2001; Despontin et al., 2005; Dong, et al., 2002; Villa, 1998).

On the basis that the creation of reliable industrial relationships is the key for better productivity and effectiveness, studies have been conducted on the durability of customer supplier relationships (Alcouffe and Corrégé, 1999), on the dynamics of these relationships (Haurat, 2002) and on their influence on inter-company costs (Brandolese et al., 2000; Harri, 2002). In addition to these works, we can mention the studies of (Toolea et al., 2002) on customer-supplier relationship performance and of (Nesheim, 2001; Smart et al., 2003; Holmlund-Rytkönen et al., 2005) on the impact of bidding on customer-supplier relationships. Other studies have rather focused on the definition of concepts in order to ensure a better cooperation between companies (Telle et al., 2004; Lauras et al., 2003). Other works have proposed an autonomous decentralized optimization system which is based on a Material Requirement Planning; we can quote the work of (Nishi et al., 2005).

On a strategic level, research work addresses collaborative networks. Collaborative networks are emerging in a large variety of forms, including virtual organizations, virtual enterprises, dynamic supply chains, professional virtual communities, virtual organization breeding environments, collaborative virtual laboratories, etc (Camarinha-Matos and Afsarmanesh, 2004; Afsarmanesh and Camarinha-Matos, 2005; Camarinha-Matos and Afsarmanesh, 
2006a). Collaborative Networked Organisation (CNO) is increasingly playing the role of reference approach to the achievement of enhanced performances in cost/time reduction and quality improvement in industrial collaboration. The fundamental assumption in ECOLEAD ${ }^{4}$ Collaborative Networked Organisations is that a substantial impact in materializing networked collaborative business ecosystems requires a comprehensive holistic approach. In (Camarinha-Matos and Afsarmanesh, 2005) the authors analyzed the main characteristics of a "discipline" in the context of collaborative networks. Based on some experience with European projects, the authors contributed in (Camarinha and Afsarmanesh, 2006b) to the discussion of assessment methods and their limitations in the case of collaborative projects. The impact creation process was also analyzed and linked to the assessment process. Indeed, assessing research progress and results in collaborative projects is a rather difficult issue for which there are no clear effective methods, and yet researchers are accountable to their funding sponsors.

In order to make advances in the interactions and information exchanges for decision making, it is necessary to introduce inter-company coordination and negotiation capabilities. Our approach proposes a Customer-Supplier (C-S) relationship control at a tactical / operational level in which all (C-S) partners negotiate according to a protocol inspired from Contract-net (Smith, 1980), in order to meet customer requirements as well as possible. In other words, our approach proposes to answer Calls For Proposals (CFPs) launched by customers companies, and to exploit supplier capacities in better ways (Mekaouche et al., 2005c). The ACE (Autonomous control Entity) of each supplier company allows self-evaluation of its performance in order to take part in negotiations within a self-organized network (Ounnar and Pujo, 2005). The proposed mechanism differs from current mechanisms in two points: Instead of having one supplier imperatively meeting customer requirements, the objective is that a

\footnotetext{
${ }^{4}$ European Collaborative Networked Organizations Leadership Initiative.
} 
whole group of potential suppliers are always able to find a solution meeting customer requirements. This represents a cultural evolution relying on "co-operative" competition rather than on "aggressive" competition.

The self-organized mechanism allows all the actors of a partnership network to operate in an "optimal" way according to their capabilities. In spite of the resource competition, the network operations lead to load smoothing allowing "weaker" partners to contribute to the performance of a global task, and thus to have an activity. This depends on two rules: the global activity volume must be approximately equivalent to the sum of the capacities of the suppliers, and is necessary that all the partners rigorously apply the same control rules. This is what we call transparency. Trust, adhesion and automation are thus major elements of our approach.

\section{HOLONIC ARCHITECTURE AND DESCRIPTION OF THE ACE}

In a context of several companies linked through customer supplier relationships, product flows are generally static after a commercial negotiation. In other words, operations of static logistics networks indicate that all the network supply chains are fixed. This approach is based on a precise commercial contract with commitments over volumes and periods. This can make flow management difficult, in particular when work overloads occur for one supplier. In a self-organized control system of a logistic network, each supply flow is considered with respect to all potential suppliers. For that, each supplier company participates in a common goal achievement (i.e., to insure supply in good conditions) by organizing its own control (Ounnar and Pujo, 2001). This is done by taking part in the definition and the evaluation of solutions, without any hierarchy, through ACE capabilities. In our proposal, decentralized self-organized control is characterized with an organizational architecture of the type flat holonic form (Bongaerts et al., 2000). Each Resource Holon has the capability with its ACE to 
self evaluate for executing a proposed task, with the aim to participate in the negotiations for allocating this task. The reference architecture PROSA is used to describe our flat holonic form. In this architecture, the basic role of the ACEs is to manage all information exchanges in the network linking the different entities and to organize information processing leading to decision making. The ACEs are in fact at the heart of the relationships between the base holons of the PROSA model:

- The Resource Holons (RH) corresponding to the companies of the logistic network partnership and which, besides the ACE capability to ensure their own control, carry production capacity characteristics;

- The Order Holons $(\mathrm{OH})$ representing the organizational aspect of the product manufacturing tasks to be performed by the resources.

- The Product Holons $(\mathrm{PH})$ providing a technical description of the manufactured products (models, sequences, etc) and thus completing production task specification.

All the information needed for performance evaluation by the ACEs is in these holons. This ACE contributes locally, on the level of the associated partner, to the assignment of the orders relating to the customer-supplier relationship. It should be mentioned that, in the case studied, the CFP is not split. Dividing a CFP is a very interesting problem that we envisage to address in continuation of this work. This brings added strength to collaboration and cooperation. In the case considered here, we assume that a job can be broken down into a series of calls for proposals but that each CFP cannot be divided during negotiation.

When a customer launches a CFP, the potential suppliers negotiate in order to provide answers to the launched CFPs and the best answer for each CFP will emerge from the negotiations. This can only be obtained if each supplier company is able to self-evaluate and to judge if it can take part in the negotiations. This leads to the idea of self-organized control. The concept of self organization is subordinated to the use of a decentralized decision 
structure and to take into account the specific behaviour of each component. With this approach, there is no estimated organization. Self organization is akin to a real-time decision making operating mode. A common goal is necessary for the organization to work; this can be translated into cooperation and negotiation terms. In the end, the solution emerges from the negotiation that makes the components of the self organized system operate.

Our horizontal holonic structure is organized around the concept of ACE. From the PROSA model, we retain the typological concepts, but we use the "basic holons" in a different way. In the proposed approach, an ACE is a decision-making centre associated with each production entity. This ACE confers the Holon Resource its self organization capacity within a set of entities having the same capacities: it is a decentralized architecture context where the entities are not controlled by a control entity of hierarchically higher decisional level. Faced with a task whose execution is proposed to a set of such production entities, each associated ACE has the capacity to selfevaluate that it can associate to it in order to take part in the negotiations for this task assignment. This architecture gives a fundamental role to the ACEs: they manage the totality of the information exchanges in the network connecting the various entities and organize the data processing sequence, which lead to the various decision-making processes. Each ACE is composed of three modules:

Interaction Module: It provides the assignment of orders to the various entities in the network. This assignment is based on decision-making processes linked to the competition between these entities (suppliers). The decision-making mechanism is based on impartial and common rules and criteria applied to all entities. The choice of an entity is based on the observation of the best response to a call for proposals for the execution of a task. The main functionalities of this module are summarized in two points:

1) The publication of information about the calls for proposals and the response to the calls for proposals coming from outside towards the optimization module or vice versa. 
2) The sorting of entities according to the received offers (updating the CFP): for each new offer which is received, the corresponding call for proposals is updated if the received offer is the first one or if it is better than the best offer already received.

The order assignment process is inspired by the Contact Net Protocol (CNP) (Smith, 1980). In CNP, the initiating entity sends out a call for proposals. Each participant reviews feasible CFPs and sends bids. The call initiator chooses the best bid and rejects the other bids. This process provides a temporarily centralized management of the CFP which was sent. With respect to Contract Net, the protocol used is simplified: many control messages are removed because it is not necessary that all the ACEs answer each request.

Indeed, the idea is to minimize the number of interactions and messages, and to remove any risk of blockage in the case of disturbances in the communication system between entities. The CFP is always sent to all the participants by an initiator entity, together with a deadline. Each participant studies all the messages concerning this CFP and builds its answer according to the contents of these messages. It answers as soon as it can provide a competing answer, i.e. only if its proposal is better than those already sent on the network. If it cannot provide a better proposal before the negotiation deadline, it does not answer. At the negotiation completion date, all the participating ACEs and the initiating ACE know which ACE is granted the task execution. Our interaction protocol is simplified compared to the protocols identified by FIPA (Foundation for Intelligent Physical Agents) and does not use a centralized data management system of the "blackboard" type.

Optimization Module: It allows the CFPs to be evaluated (Ounnar and Pujo, 2004) (Mekaouche et al., 2005b). Each ACE will estimate its own capacity to respond to the call for proposals and will deduce its own performance, according to criteria common to all the ACEs. The selected multicriteria method was the Analytic Hierarchy Process (AHP) method (Saaty, 1996). The evaluation of the supplier company is carried out using the AHP method in 
order to classify the CFPs the supplier can perform. Thus this multicriteria method is used in order to choose, among several CFPs, the CFP which provides the best performance for the company. The application of this method requires a set of quantitative or qualitative criteria. Among the quantitative criteria, there is the operating time of the CFP. This data depends on the planning state and on the availability of equipment. It is obtained by the planning module. Planning Module: The planning module manages the production planning of the entity in order to study the possibility of inserting the CFP in this planning. The planning module calculates the operating time of a call for proposals. The calculations are performed using an analytical method based on various planning states of the production system. According to the available space the method finds the best possible insertion. Then, the planning module sends the operating time which has been calculated to the optimization module. This module manages CFP status. Indeed, it manages the status of the CFPs being processed according to the evolution of task assignments and CFPs answers:

- "Negotiable" CFP: a call for proposals being negotiated for which a first answer was possibly received, providing a performance reference;

- "Engageable" CFP: a call for proposals which is temporarily assigned to the ACE because its performance is the best one at this moment; this status can be lost if a better offer (response) appears and regained if, for example, new possibilities appear on the ACE planning;

- "Pre-engaged" CFP: an 'Engageable' call for proposals which is the next one to be processed on the ACE planning (the negotiation completion date has been reached);

- "Committed" CFP: a call for proposals that was pre-engaged and whose implementation is on-going or about to start, which makes it definitively placed on the Entity planning at the commitment date of this entity. 
Let us precise that the planning is dynamic. When a FCP is removed from the planning, because another supplier has given a better offer, the other CFPs located downstream of the removed CFP are re-evalued because the performance may be better.

A partner can be a customer, a supplier, or both. One of the customers has launched a CFP on the network. This CFP will be provided with a certain number of information items. The CFP frame is mainly composed of the following pieces of information: Identification of the CFP: Name of the transmitting entity (customer company), CFP number; CFP type (description of the requested product); CFP state; quantity excepted by the customer; delivery time; end of negotiation lead time. All the ACEs which are connected to the network will receive this CFP. Once the CFP is received by a given ACE, the interaction module will check the technical feasibility of the CFP and transmits the CFP to the optimization module which applies a multicriteria method in order to classify all the received CFPs, according to the entity processing capacities. The application of this method requires a set of quantitative and qualitative criteria, some of which, such as delivery lead time, expected quantity, etc, are defined by the customer company in the CFP. Other criteria are parameterized by specific supplier characteristics, such as lead time, order delivery time, delivery cost, order cost. The operating time is one of the criteria defined by the supplier company. This data is supplied by the planning module. The interaction module matches the performance given by the optimization module with the better known performance and sends it to the network if it is the best one (Fig. 1). The various messages circulating on the network can be summarized as follows: CFP, RCFP (Response to Call For Proposals), LCFP (Local Call For Proposals launched by the entity), RLCFP (Response to a Local Call For Proposals: response proposed by one partner of the network), ERCFP Entity Response to a Call For Proposals launched by a partner).

\section{Insert Fig. 1 here}


The RCFP frame comprises following pieces of information: Identification of the RCFP: Name of the answer transmitting entity, Name of the CFP transmitting entity, CFP number; Performance of this entity on the CFP and its commitment date.

Interactions between the base holons and an $\mathrm{ACE}$ are shown in Fig. 2. A $\mathrm{CFP}_{\mathrm{i}}(\mathrm{Call}$ For Proposals) is received by the ACE. Each CFP is composed of information coming from the Product Holon and Order Holon. The value of the performance (Perf) is sent on the network via the $\mathrm{RCFP}_{\mathrm{i}}$ (Response to the Call For Proposals i). In order to obtain this performance, the optimization module needs the operating time data. This latter is obtained from the planning module which is in relation with the Resource Holon (the company). It should be mentioned that, in the long term, the objective is to connect the ACE to the company information system which addresses internal planning issues.

Each ACE has privileged exchanges within the Resource Holon it is associated with, which provides information on its planning, its capability, etc. The data associated with the Order Holons and the Product Holons circulate in the network via Calls For Proposals (CFPs). Products are associated with Product Holons describing them in their progress, according to their route, along the production system. Their progress is managed by the evolution of the Order Holons which trigger production tasks. In summary, the ACEs control the Resource Holons while ensuring allocation of the Order Holons that concern the production of the Product Holons.

\section{Insert Fig. 2 here}

The assignment of orders is based on the search for the best response to a call for proposals submitted by a customer company. The solution adopted to make the set of these entities operate will be obtained by emergence. In other words, the solution that appears to be the most efficient in terms of the evaluation criteria will be adopted.

In the following section, the evaluation process of each Resource Holon is described. 


\section{PERFORMANCE EVALUATION}

The use of a multicriteria method to evaluate each RH is essential to ensure that the selected supplier company will meet customer's requirements. The selected supplier should be reliable and able to satisfy the customer's needs in terms of quality, quantity, on-time delivery, etc. The supplier evaluation process allows monitoring the ongoing relationship between suppliers and customers. The multicriteria decision aims at providing tools to a decision maker enabling him to progress in the resolution of a problem where several points of view, often contradictory, must be taken into account. A survey of methods using multiple criteria (Ounnar and Ladet, 2004) has led us to select a method called Analytic Hierarchy Process (AHP) presented by (Saaty, 1996). AHP has advantages over other decision-making approaches (Wedley, 1990), (Vargas, 1990). These include the ability to: (i) handle tangible and intangible attributes; (ii) structure the problems hierarchically to gain insights into the decision-making process; and (iii) monitor the consistency of the judgments of a decisionmaker. The AHP was chosen as the multicriteria method because of its capability to quantify and rank the alternatives using a simple pair-wise comparison of criteria (Harker, 1989). The AHP has demonstrated robustness across a range of application domains (Saaty, 1996).

Each ACE estimates its own capacity to respond to a call and deduces its own performance according to criteria common to all the ACEs. This performance allows a real differentiation of the order assignment solutions, since the intrinsic behaviour of each company in the network is taken into account in real time. Realizable calls for proposals are evaluated using a multicriteria method in order to classify them and to deduce the most convenient one for the entity. Then, the calculation of the entity performance with regard to the selected call for proposals can be carried out. 
The AHP multicriteria method makes it possible for each supplier company to sort the calls for proposals which they can carry out (Ounnar et al., 2004) and select a convenient one. The first step for the implementation of the multicriteria algorithm based on the AHP method is to derive an adequate system of indicators providing each supplier company with the ability to evaluate their performance (See Table 1). Eventually, we are able to evaluate the performance of the call for proposals ranked first by each supplier company. More detailed description of the AHP decision mechanism is given in (Ounnar et al., 2007).

\section{Insert table 1 here}

In the proposed approach, each customer company has the possibility to indicate that it prefers to work with a designated supplier company, knowing the possible productivity loss that such a decision might yield. Each supplier company can define its own preferences regarding the criteria and indicators that are used to evaluate his performance for identifying the calls for proposals (CFPs) on which it will negotiate. Thus, this approach makes it possible to ensure automatic order distribution through negotiation between potential suppliers able to respond to a CFP, based on common and impartial rules, while leaving some degrees of freedom to each partner.

All partners rigorously apply the same control rules. The ACE is a decision module containing the algorithms allowing the operation of these rules. These rules are the same for all the partners. They are parameterized locally by each company, on parameters allowing the production capacity to be described. They are also balanced by other parameters controlled by the network and aiming at judging the adequacy between the company commitments and the real offers of performance. Thus, a company which systematically respect its commitments will see these parameters neutralized. On the other hand, each company trying "to cheat" about its descriptive parameters will not be able to respect its commitments (delay, quality, time, etc) and will be penalized on these "network" parameters (quality, etc). 
The logistic network is built on a honest and transparent partnership. An important condition to the good operation of this type of relationship is the existence of mutual trust among partners. In this type of network, it is necessary to sensitize and engage the logistics men in a policy of permanent progress, made up of continuous improvement in order to maximize the economic potential. The customer companies must, besides the internal optimization of their production but in connection with it, optimize their relations with their suppliers. Each supplier company positions itself with regard to the various customers companies and shows its capacity to provide need for support while letting each partner use its own assets.

Thus, the proposed approach can be applied within a logistic network where there is mutual trust between partners. Indeed, in order to have a perennial Customer-Supplier relationship in a dynamic partnership, it is necessary to use a set of tools, such as: the contractorization of the relationships, development of trust between partners and implementation of a system to assess the suppliers that are relevant, coherent and motivated. Trust, reciprocity and shared goals are the principal components of a strong Customer-Supplier relationship.

\section{DEVS MODELLING AND INTEGRATION IN HLA ENVIRONMENT}

To validate the self-organized approach by simulation, the ACE was modelled with the DEVS (Discrete EVent system Specification) formalism (Mekaouche et al., 2005a), developed for the modelling and the simulation of dynamic systems with discrete events. It allows the formalization of modular and hierarchical models. It is possible to carry out formal checks of a DEVS model, which is a precious help when designing models. (Zeigler, 1976) presents the concept of coupled DEVS model which describes the system as a network of components. The developed models were integrated into a HLA distributed simulation environment, which enabled us to produce a prototype for simulating the self-organized approach. 


\subsection{Modelling of the ACE using the DEVS formalism}

The DEVS formalism was proposed by (Zeigler, 1976) to allow a rigorous modelling with discrete events. In particular, he introduced the possibility of autonomous evolution of the model thanks to the lifespan of the states and to the internal transition function. The concept of DEVS coupled model describes the system as a network of components, which can be either DEVS atomic models or DEVS coupled models. This makes it possible to introduce a concept for formalization of modular and hierarchical models (See Appendix 1).

\subsubsection{DEVS-ACE Coupled Model}

The behaviour of ACEs is modelled using the DEVS formalism. The ACE modules are modelled using a coupled DEVS model (See Fig. 3). We describe below the information that are received and dispatched by the entity.

\section{Insert Fig. 3 here}

a) Input ports: $\mathbf{X}=\{C F P 1, \mathrm{RCFP} 1$, RLCFP1, LCFP0, Init $\}$

CFP1 $:=\{$ CFPFrame $\}:$ it indicates the arrival of a given CFP from the network including a CFPFrame.

RCFP1 := $\{$ RCFPFrame $\}$ : it indicates the arrival of a given RCFP from the network including a RCFPFrame.

RLCFP1 := $\{$ RCFPFrame $\}:$ it indicates the arrival of a response for a given LCFP proposed by a given partner on the network including a RCFPFrame.

LCFP0 : $=\{$ CFPFrame $\}$ : Allows the reception of a signal in the form of a CFP frame coming from the production system, resulting from a breakdown or a resource shortage.

Init $:=\{$ CFPFrame $\}$ : list of CFPFrames, necessary to initialize the planning.

b) Output ports: $Y=\{L C F P 2, E R C F P 1\}$

LCFP2 $:=\{$ CFPFrame $\}$ : allows sending a local CFP defined by a CFPFrame. 
ERCFP1 : $=\{$ RCFPFrame $\}$ : allows sending a response of the entity concerning a given CFP, defined by a RCFPFrame.

CFPFrame and RCFPFrame are object classes defining a CFP and a RCFP, respectively.

\section{c) Component set}

$\mathrm{D}=\{$ Interaction, Optimization, Planning $\}$

\section{d) Input links}

$\mathrm{EIC}=\{((\mathrm{ACE}, \mathrm{CFP} 1),($ Interaction, $\mathrm{CFP} 1)),((\mathrm{ACE}, \mathrm{RCFP} 1),($ Interaction, RCFP1) $),((\mathrm{ACE}$, RLCFP1), (Interaction, RLCFP1)), ((ACE, Init), (Planning, Init)), ((ACE, LCFP0), (Planning, LCFP0) $\}=$ A

\section{e) Output links}

$\mathrm{EOC}=\{(($ Interaction, LCFP2) $),(\mathrm{ACE}, \mathrm{LCFP} 2),(($ Interaction, ERCFP1), (ACE, ERCFP1)) $\}$ $=\mathrm{B}$.

\section{f) Internal links}

$\mathrm{IC}=\{(($ Interaction, OC), (Optimization, OC) $),(($ Interaction, DO $),($ Optimization, DO $))$, ((Interaction, CFP2), (Optimization, CFP2)), ((Optimization, CFP3), (Planning, AO3)), ((Optimization, DO1), (Planning, DO1)), (Optimization, OC1), (Planning, OC1)), (Optimization, ERCFP), (Interaction, ERCFP)), ((Optimization, LCFP1), (Interaction, LCFP1)), ((Planning, CFPDate), (Optimzation, CFDate)), ((Planning, LCFP), (Optimization, LCFP)), (Planning, CFPRevalued), (Optimization, CFPRevalued))\}.

\subsubsection{Description of DEVS models}

The Interaction, Optimization and Planning DEVS models are also coupled DEVS models, which respectively model the behaviour of the Interaction, Optimization and Planning modules. 


\subsubsection{Interaction Model}

In order to operate the functionalities of this module, we modelled it using a coupled DEVS model composed of three atomic models (See Fig. 4):

- "RCFP/ERCFP Management" sub model: it manages the response to a CFP and the entity response to a CFP.

- “CFP/LCFP Management” sub model: it manages CFPs and local CFPs.

- "RLCFP Management" sub model: it manages the responses to a local CFP.

\section{Insert Fig. 4 here}

\subsubsection{Optimization Model}

This model (See Fig. 5) allows the ACE to self-evaluate its performance with respect to the received CFP, in order to estimate its own capacity to respond to it. In order to operate these functions, we modelled it using a coupled DEVS model composed of four atomic DEVS models.

- "LCFP/OC Management" sub model: it manages local CFPs and OCs (Order Change). It also receives OCs from the interaction module; it transmits them to the planning module so that the state of the corresponding CFPs can be changed.

- "CFP/DO Management" sub model: it manages CFPs and DOs (Delete Order). It makes it possible to provide a list of the CFPs having an operating time to the "Application_AHP" model. For that, it initially receives a CFP coming from the interaction model; it transmits it towards the planning model so that the operating time can be calculated. The list of CFPs that are sent to the "Application_AHP" sub model must contain at least two CFPs. Moreover, the "Application_AHP" sub model should not be in a busy state. This sub model can also receive a DO coming from the interaction model; it transmits it towards 
the planning model in order to suppress a CFP for which another entity provides a better response. Thus, the planning module proceeds to the revaluation of the operating time of all CFPs being downstream of the removed CFP.

- “Application_AHP” sub model: it is based on the Analytic Hierarchy Process (AHP) method which is a multicriteria method that makes it possible to obtain the "BestCFP" which will be sent to the "Calcul_Perfomance" sub model which allows the performance to be calculated. In addition, it allows the remaining list to be sent to the "CFP/DO management" sub model to inform it of its availability.

- "Calcul_Perfomance" sub model: it makes it possible essentially to calculate the performance of the selected CFP "BestCFP" during the application of the AHP method. Before calculating this performance, the model checks if its operating time was reevalued. If it is the case, it extracts the new date to calculate the final performance. The module broadcasts the recalculated performance.

\section{Insert Fig. 5 here}

\subsubsection{Planning model}

In order to operate the planning functions (described in section 3), we modelled it using a coupled DEVS model composed of two atomic DEVS models (See Fig. 6).

\section{Insert Fig. 6 here}

- “Operating Time Management" sub model: on receipt of a CFP, it calculates its operating time. This model can also receive a state order change for a given CFP. Therefore, the CFP state changes from 'negotiated' state into "Engageable" state by applying the function "Change". It can also receive the order to delete from its planning a CFP for which the entity was "Engageable"; it thus proceeds to the revaluation of the operating 
time of all CFPs being downstream of the removed CFP. The result of this suppression is a list of revalued CFPs.

- "LCFP Management" sub model: it can launch a LCFP towards the optimization model. For that, it receives the identification of this LCFP. Then, it broadcasts it outside via the other models.

\subsection{Integration of the ACE models in an HLA environment}

The different modules of an ACE were modelled using an atomic DEVS model. To validate the proposed approach, it is necessary to validate the global model of a partnership network. For that, we have integrated the set of ACE models in a distributed simulation environment HLA. We present the basic principles of HLA and the integration of the ACE models in this environment.

\subsubsection{High Level Architecture (HLA)}

The High Level Architecture (HLA) developed by the Defence Modelling and Simulation Office (DMSO) of the Department of Defence (DoD) defines an approach to integrate the federates (components of simulation, which represent the Autonomous Control Entities (ACEs)) in one distributed simulation system, called federation (which represents the logistic network). It facilitates the reusability and interoperability of the simulations. Reusability means that the models of the simulation components can be reused in various simulation applications without any recoding needed. Interoperability implies the capacity for combining simulation components on distributed platforms of various types. HLA is formally defined by three components: 
- HLA rules: recapitulate the principles of HLA. These principles are summarized in 10 rules defining the operation of the federate ( 5 rules) and of the federation ( 5 rules) (IEEE P1516).

- HLA interface specifications: describe the execution services provided to a federate by the Run-Time Infrastructure (RTI). They indicate how federates interact during the federation execution (IEEE P1516.1). The RTI software complies with the HLA interface specifications.

- OMT (Object Model Template) is the description of the elements (objects and interactions) which are shared through a federation (IEEE P1516.2). HLA requires that each federate and each federation document its object model by using the OMT. For that, HLA specifies two types of objects models. The first is the Federation Object Model (FOM) which describes the set of the objects, attributes and interactions which are shared through the federation. The second is the Simulation Object Model (SOM) which provides information about the faculty of simulation for an exchange of information when it is part of a federation.

\subsubsection{Relations among the various components of a simulation}

To integrate the ACE models in the HLA environment, we split the ACE federate into (See Fig. 7):

- Simulators of the DEVS-ACE Models;

- Local Coordinator;

- Federation Object Model (FOM);

- Interface between the model simulators and the RTI.

Insert Fig. 7 here 


\subsubsection{Simulators of the DEVS-ACE Models}

They insure the simulation of the atomic models by using the functions defined in DEVS to generate their behaviour. They calculate the changes of states and possibly the output events resulting from the reception of the internal events according to the functions defined by DEVS. To represent the DEVS-ACE models, we used two abstract classes:

- One class for the atomic DEVS models "AtomicModel", from which the atomic models of DEVS-ACE inherit. These models contain all the methods defined in DEVS.

- The second class for the coupled DEVS models "CoupledModel", from which the coupled DEVS-ACE models inherit. The various methods of this class are invoked from the local coordinator in order to select the atomic model influenced by a specific event.

\subsubsection{Local Coordinator}

It insures the routing of the messages among the various simulators of atomic DEVS models according to the relations of coupling, i.e. all the relations of coupling that exist among the DEVS-ACE models. It handles a scheduler containing the input and output events. It also preserves the relations of coupling among its simulators.

\subsubsection{Federation Object Model (FOM)}

Common data from the different federates SOMs (Simulation Object Models) make it possible to produce the FOM of the ACE/HLA federation. They are of two types: objects and interactions. The objects are persistent shared information, while interactions are temporary data (only emitted and received). The shared objects and interactions in a federation are defined in table form.

For example, in the FOM we find the Interaction Class Structure Table. Indeed, interaction classes are necessary to establish communication among federates. 


\subsubsection{Interface between the model simulators and the RTI}

The RTI manages the communication, the FOM data exchange among the different federates, the recovery, the organization and the distribution of the messages exchanged within a global simulation. The RTI also plays the difficult role of insuring temporal synchronization among federates while respecting the principle of causality (the order of treatment of events). The role of the simulation kernel is to manage the simulation. It receives messages coming from the RTI via the code inherited from the FederateAmbassador class. It listens to each event produced by the user interface. It also invokes the methods of RTIAmbassador to interrogate the RTI.

\subsection{Simulation Prototype}

The self-organized approach described in the above sections was implemented in a prototype using Java language. Starting from the interface (See Fig. 8), a partner can become a member of an enterprise network (A) or resign from a network (B). The interface offers each ACE the possibility to launch local calls for proposals (C). Each ACE can receive answers to local calls (D). It can also receive answers to calls for proposals launched by other members of the enterprise network.

\section{Insert Fig. 8 here}

Let us suppose that a customer company (customer1) (See Fig. 8) broadcasts on the network a call for proposals containing the following information: the work type to be performed (in technical terms), the maximum expected delay (here, 10 days), etc.). The CFP will be broadcast to all the network partners through the HLA interactions. The Broadcasting of the CFP is done thanks to HLA interactions, by using the methods of RTIAmbassador (See Section 5.2.2.4). The figure 9 shows a CFP reception by a supplier company (Supplier 2). 


\section{Insert Fig. 9 here}

The prototype presented above was used to validate the self-organized control approach with a set of tests. The simulation kernel (See Section 5.2.2.4) translates the received CFP into a DEVS event and sends it towards the corresponding simulator of the atomic model via the local coordinator. Before calculating the performance of this CFP, we must check its feasibility according to the company's activities and whether the calculation of its operating time has been done. Once the operating time is calculated, the calculation of the performance can be made by the "Calcul_Performance" Optimization sub model (See Section 5.1.2.2). The performance is sent as an ERCFP (See Fig. 10).

\section{Insert Fig. 10 here}

The key role of this atomic model is to calculate the performance of the selected CFP (BestCFP) during the application of the AHP method. On receipt of a BestCFP, the Calcul_Performance sub model passes into the "Seek_CFP" state to check if the BestCFP realization date has been re-evalued. If such is the case, it extracts the new date, then it passes into the "Insert1" state to calculate the performance and to send the response to the Interaction model. Otherwise, the sub model passes into the "Insert" state to calculate the performance of the BestCFP, and forwards it to the Interaction model so that the response can be diffused on the network. This model can also receive a CFP with its re-evalued realization date (CFPRevalued). Consequently, the state sub model changes and passes into the "Seek_ERCFP" state. The objective being to check if the entity has already sent a response relating to this CFP. If such is the case, the sub model passes into the "Crush" state, and then it recomputes the new CFP performance, replaces the answer already proposed by the new one whose performance has just been recomputed and then diffuses the recomputed performance. If the received CFP, whose realization date has been re-evalued, has not already 
been selected using the AHP method, the sub model inserts it in the re-evalued CFP list, and to do this it passes into the "Insert2" state.

Finally, before diffusing the calculated answer, it is necessary to compare the response with the one which circulates on the network. This is done by the "RCFP/ERCFP Management" Interaction sub model (See Section 5.1.2.1) (See Fig. 11).

\section{Insert Fig. 11 here}

This sub model can receive a response to a given CFPi (RCFPi). On receipt of this response, this sub model passes into the "Seek_RCFP" state, then checks if there is already a response concerning this CFP. If it does not find a response for this CFPi, it passes into the "Insert1" state to insert this response in a list. On the other hand, if it finds a response concerning this CFP, it passes into the "compare2" state, to compare the two responses. There are two possibilities:

- the received response is higher than the existed one : then the sub model passes into the "Crush1" state, and replaces the old response by the new one.

- the response comes from the entity: then it sends a suppression order towards the planning model. This means that the entity is no longer the best for this CFP.

This sub model can also receive a ERCFPi response for a given CFP, coming from its Optimization model. Before diffusing this response on the network, it must make sure that it is the best for this CFP. For that, on receipt of a response "ERCFP", the sub model passes into the "Seek_ERCFP" state, to carry out a research and to see whether there is already a response to this CFP. If it does not find a response concerning this CFP, then the sub model passes into the "Insert2" state, to insert the "ERCFP" response in a list and diffuses it on the network because it is the best at this moment. On the other hand, if a response for this considered CFP already exists in the list, the sub model must then carry out a comparison in 
terms of performance. For that, the sub model passes into the "compare1" state. There are two possibilities:

- If the sub model has a better performance, it first sends a state change order of the considered CFP to the Planning model by the means of the Optimization model (it passes from the "negotiable" state into the "Engageable" state). Then it passes into the "Crush2" state to replace the response found in the list by that of the entity and, finally, diffuses it on the network.

- If the sub-model has a lower performance, it sends an order of suppression of this CFP to the Planning model, because the entity is no longer the best.

\section{CASE STUDY}

The case study is related to a network made up of 17 companies (A1, A2, A3, A4, B1, B2, B3, C1, C2, C3, D1, D2, D3, E1, E2, M1, M2). Each company is characterized by its name, activities, activity codes, load per activity, maximum capacity per activity and number of resources per activity. These elements are summarized in table 2 .

\section{Insert table 2 here}

In a first step, networked enterprise operations in the context of static logistics chains control (constant flows and quantities) will be studied by modelling and simulating a set of relationships between companies. These companies can produce 16 types of products coming from 5 base products. There are 16 logistic chains corresponding to the flows of the 16 different product types. The flows of the sixteen types of products and the associated chains were thus studied. Let us take the example of the finished product PF1, which generates two types of products, having the same bill of material, the same route and different manufacture unit times. The logistic chain they go through is shown in figure 12 .

\section{Insert Fig.12 here}


In a second step, the same network (same production capacity, same processed products) will be studied in the context of dynamic logistics chains self-organized control. A comparison between the two contexts will be analyzed. The tests were designed so that small disturbances introduced in the nominal operations (such as an increase in ordered product quantities) generate strong organizational perturbations in flow progress (blockage, saturation). We thus performed tests with the data in a nominal operation configuration and then in a disturbed operation configuration. The study was focused on two types of disturbances:

- Test of saturation limit: this type of test concerns the introduction of a disturbance into the companies carrying the most activities. The disturbance consists in customers launching orders for additional batches during the same period (one week).

- Test of load accumulation conjunction: in this type of disturbance, the considered companies are those making several products. In the same context as with the first type of disturbance, we supposed that during the same week supplier companies received orders from their customers companies for additional batches.

\subsection{Network Analyze following the saturation limit test}

When the approach was studied in the context of static logistics chains control, we analysed the influence of disturbances of the first type for companies A2, B1 and M1 whose work load exceeded their maximum capacity. Figure 13 shows the overshooting capacity for A2, B1 and M1, due to the injected disturbances. "INIT" represents the initial load for each company (See. Table 2). "Dist1_Type1" and "Dist1_Type2" represent the first type of disturbance concerning the type 1 and type 2 products, respectively.

Insert Fig. 13 here 
A2 deals with the additional orders, which generates its overload and, as A2 has subcontracted conditioning and printing (B1 and M1), this also generates a significant overload for B1 and M1.

In the context of dynamic logistics chains self-organized control, CFPs were launched according to the steps of fabrication of the two types of products (PF1-Type1, PF1-Type2). Figure 14 illustrates the new flows of these two types of products.

\section{Insert Fig. 14 here}

The graphs presented on figure 15 highlight the load balance for the companies that have taken the precedent CFPs. "INIT" represents the initial load for each company (See. Table 2). "DistX_TypeY" represents the launched CFP, which relates to the disturbance "X", for the product of type "Y". We can note that these companies would not consider the calls for proposals leading to overload.

\section{Insert Fig. 15 here}

A summary is given in the form of curves on figure 16. The self-organized approach allows a realistic solution, and thus a feasible one, to be obtained without generating induced overload for the other companies. On the other hand, the static logistics chains control approach generates operation problems for the network since it proposes solutions with overloads.

\section{Insert Fig. 16 here}

\subsection{Network Analysis following the load accumulation conjunction test}

For this type of disturbance, the study was centred on the companies belonging to several chains: D1, M2, B3, E1, D3, C3. This led us to consider seven out of the sixteen product types (types 3, 4, 5, 6, 7, 10 and 12) and 6 companies. The disturbance consisted in increasing the ordered quantities of each of the seven product types. As for the disturbance of type 1 , for the seven logistics chains a reporting system collects data on the circulating products, such as 
batch arrival date or total time in the company, in order to study the impact of the perturbation on the chains. A first analysis of the static logistic chain control model enabled us to highlight the overshooting capacity of the companies involved in the flow of one of the seven types of products concerned with the disturbance. This led to delivery delays on the seven product types and also on other products. There was thus an impact on other chains.

Contrary to the static logistics chains control model in which the chains are fixed and the customers launch orders only to their own suppliers, in the proposed dynamic logistics chains self-organized control model customers launch CFPs on the network, then the potential suppliers negotiate to meet customer needs as well as possible. So, the seven product chains are built by taking into account the real situation of the supplier companies. The building of these new chains is progressively made by allocating a launched CFP to the supplier having the best performance for this CFP. Best performance allows allocating the related order to the best suited supplier for the CFP, which guarantees a better customer satisfaction. In addition, a company cannot take a CFP if its maximum capacity is not compatible with it. This generates a load smoothing for each company and eliminates the delay problem due to overshooting capacity caused in the static logistics chains control approach.

In order to show the load smoothing for each considered company, we represented graphically the load for each company compared to its maximum capacity, and also showed the occupation rate for each company studied with the two approaches. Fig. 17 shows the occupation rate compared to the total load and Fig. 18 shows the occupation rate for each company compared to its activities.

Insert Fig. 17 here

Insert Fig.18 here

\subsection{Result analysis}


From the curves made for each type of disturbance and each approach for the companies concerned with the disturbance, and from the superposition of capacity and load for each company, we can observe the balance and load smoothing for all the companies in the selforganized control context. The charts related to the static logistics chains control context show an overshooting capacity for most of the companies considered in the study. Generated overshooting capacity had a direct impact on the delivery of some products. Through the analysis of these results we could point out that some products were delivered with delay. In the static logistics chains control context, the disturbance yields an overload for 11 companies. In the context of dynamic logistics chains self-organized control, we can notice that there is at worst systematically the same load and at best a reduced load for the same service delivered by the logistic network.

\section{CONCLUSION}

The approach presented here aims at ensuring collectively the distribution of the orders coming from various customers companies while respecting the interest of each customer company, in a context in which there is at the same time autonomy and trust, in order to obtain a balance between load and capacity for each supplier and a load smoothing between the various suppliers. For that, we proposed a new approach of logistic network control. The proposed approach is based on a self-organized control model in which a decision system manages the operation of a set of entities belonging to a partnership. The proposed selforganized control is characterized by an organisational architecture of the flat holonic form type. To each Resource Holon is associated a decision-making unit named "Autonomous Control Entity" (ACE), enabling self-evaluation with respect to received calls for proposals, to take part in the negotiation and evaluate solutions in the absence of hierarchy. The fundamental role of the ACEs consists in managing all the information exchanged between 
the various network entities and in organizing the data processing leading to decision-making processes. The DEVS models of the ACE have been presented in this paper. The integration of these models into a HLA distributed simulation environment has been described, and the simulation prototype has been presented.

A comparison with the static logistics chains control approach has been made from a case study. The tests were designed so that small disturbances introduced in the nominal operations (such as an increase in ordered product quantities) generated strong organizational perturbations in flow progress (blockage, saturation). We thus performed tests with data related to normal operating and to disturbed operating. The comparison of the results obtained for each type of disturbance enabled us to highlight the benefits of the proposed approach.

This approach provides a balance between load and capacity for the supplier company and produces a load curve smoothing among the network suppliers with the long-term objective of establishing a fair system among them. It also leads to the sharing of earnings, the optimization of resources, a reduction in the malfunctioning, and an increase in productivity for the whole supply chain.

This approach allows data confidentiality for the different network partners. Indeed, a supplier company provides only a single piece of information to the network which is its performance value for a given CFP. Consequently, the approach can be applied within a logistic network in which there is mutual trust among the partners or in a multi-sited company.

We intend to extend this work and consider CFP partitioning. CFP partitioning gives more strength to collaboration and cooperation.

To conclude, let us note that if the optimization of logistic networks is to be efficiently implemented, a change in attitude and philosophy is needed. Companies must get together to propose a general service, rather than trying to compete. They must work together in seeking better productivity. New ways of supplying and subcontracting require improved dialogue and 
a cultural evolution relying on cooperation rather than on confrontation. This is why our work perspective is oriented towards seeking a professional sector to conduct real life experimentation or to run a simulation in parallel to real operations in order to compare results and to definitively validate our approach.

\section{REFERENCES}

Afsarmanesh, H., and Camarinha-Matos, L.M. (2005) A Framework for Management of Victual Organization Breeding Environments. Proceedings of PRO-VE'05 - Collaborative Networks and their Breeding Environments, Springer, 26-28 Sept 2005, Valencia, Spain.

Alcouffe, C., and Corrégé, N. (1999) L'évaluation des performances dans les organisations en réseaux de soustraitants: l'exemple de l'Aérospatiale Matra Airbus. Revue Française de Gestion Industrielle, 18 (4), 27--42

Bongaerts. L., Monostori. L., McFarlane. D., and Kadar, B. (2000) Hierarchy in distributed shop floor control. Computer in Industry, 43, 123--137.

Brandolese A., Brun A., and Portioli-Staudacher A. (2000) A Multi-Agent approach for the capacity allocation problem. International Journal of Production Economics, 66, 269-285.

Brito, C.M., and Roseira, C. (2003) A Model for the Understanding of Supply Chain Networks. 19th annual Industrial Marketing and Purchasing Conference, University of Lugano, $4^{\text {th }}-6^{\text {th }}$ Septembre, Lugano, Switzerland.

Camarinha-Matos, L.M., and Afsarmanesh, H. (2004) Collaborative Networked Organizations - A research agenda for emerging business models, Springer, New York.

Camarinha-Matos, L.M., and Afsarmanesh, H. (2005) Collaborative networks: A new scientific discipline. Journal of Intelligent Manufacturing, 16 (4-5), 439-452.

Camarinha-Matos, L.M., and Afsarmanesh, H. (2006a) Towards a reference model for collaborative networked organizations. Proceedings of BASYS'06 (Springer), 4-6 Sept 06, Niagara Falls, Canada.

Camarinha-Matos, L.M., and Afsarmanesh, H. (2006b) Results assessment and impact creation in collaborative research-An example from the ECOLEAD project. Technovation, 27 (1-2), 65--77.

Chen, H., Amodeo, L. ,and Chu, F. (2001) Modelling and performance evaluation of supply chain with Batch deterministic and stochastic petri nets. 13th European Simulation Symposium, pp. 415-419, October 2001, Marseille.

Cousins, P.D., and Spekman, R. (2003) Strategic supply and the management of inter- and intra- organizational relation ships. Journal of Purchasing and Supply Management, 9 (1), 19--29

Deen, S.M. (2003) Agent-Based Manufacturing - Advances in the Holonic Approach. Springer-Verlag Ed, ISBN 3-540-44069-0.

Despontin, E., Briand, C., and Esquirol, P. (2005) Aide à la décision pour une coopération inter-entreprises : une approche par contraintes. Journal Européen des Systèmes Automatisés, 39 (7), 799--818

Dong, J., Zhang, D., and Nagurney, A. (2002) Supply chain networks with Multicriteria Decision-Makers. Transportation and Traffic Theory in the 21st Century, M.A.P, pp. 179-196.

Faems, D., Van Looy, B., and Debackere K. (2005) Interorganizational collaboration and innovation: towards a portfolio approach. Journal of Product Innovation Management, 22 (3), 238--250

Fujimoto. R. (2003) Distributed Simulation Systems. Proceedings of the 2003 Winter Simulation Conference, 124-134.

Harker, P.T. (1989) The art and science of decision making: The Analytic Hierarchy Process: Applications and Studies, Springer-Verlag ed. 
Harri, I.K. (2002) Accounting in customer-supplier relationships: Developing cost management in customersupplier relationships: three case studies. Proceedings of the 3rd Conference on New Directions in Management Accounting: Innovations in Practice and Research, Vol 2, 699--716, December 2002, Brussels, Belgium.

Holmlund-Rytkönen, M., and Strandvik, T. (2005) Stress in business relationships. The Journal of Business and Industrial Marketing, 20 (1), 12--22 (11).

IEEE P1516, Draft Standard for Modeling and Simulation (M\&S) High Level Architecture (HLA) - Framework and Rules.

IEEE P1516.1, Draft Standard for Modeling and Simulation (M\&S) High Level Architecture (HLA) - Federate Interface Specification.

IEEE P1516.2, Draft Standard for Modeling and Simulation (M\&S) High Level Architecture (HLA) - Object Model Template (OMT) Specification.

Lauras M., Parrod N., and Telle O. (2003) Proposition de référentiel pour la notion d'entente industrielle : trois approches dans le domaine de la gestion des chaînes logistiques. Revue Française de Gestion Industrielle, $22(4), 5--30$

Mekaouche. L., Ounnar. F., Pujo. P., and Giambiasi. N. (2005a) Customers - Suppliers relationship self organized control modeling using DEVS formalism. IMACS'05 - the 17th IMACS World Congress on Scientific Computation, Applied Mathematics and Simulation, Paris, France.

Mekaouche. L., Ounnar. F., Pujo.P., and Giambiasi. N. (2005b) Self Evaluation of Company's Performance in Partnership Network. IEEE International Engineering Management Conference (IEEE - IEMC) - St. John's, Newfoundland, Canada.

Nesheim, T. (2001) Externalization of the core: antecedents of collaborative relationships with suppliers. European Journal of Purchasing \& Supply Management, 7, 217--225.

Nishi. T., Konishi. M., and Hasebe. S. (2005) An autonomous decentralized supply chain planning dor multistage production processes. Journal of Intelligent Manufacturing. 16, 3, 259--275.

Ounnar F., and Ladet P. (2004) Consideration of machine breakdown in the control of flexible production systems. International Journal of Computer Integrated Manufacturing System, 17 (1), 69--82.

Ounnar. F., and Pujo. P. (2001) Décentralisation des mécanismes de pilotage de la relation donneurs d'ordres / fournisseurs. Actes du 4e congrès International de Génie Industriel, vol.2, 1175--1185, France.

Ounnar. F., and Pujo. P. (2005) Supplier evaluation process within a self-organized logistical network. International Journal of Logistics Management, 16:1, 159--172.

Ounnar. F., Pujo. P., Mekaouche. L., and Giambiasi. N. (2004) Decentralized Self Organized Control of a Partnership Network in an Intelligent Supply Chain. IMS International Forum 2004: Global Challenges in Manufacturing, Italy.

Ounnar, F., Pujo, P., Mekaouche, L., and Giambiasi, N. (2007) Customer-supplier relation-ship management in an intelligent supply chain network. Production Planning \& Control, 18(5), 377--387.

Pradosh, N., Sandhya, G.D. and Mrinalini, N. (2005) Supply chain as knowledge management. International Journal of Logistic Systems and Management, 1 (2/3), 267--278.

Saaty. T. (1996) Multicriteria Decision Making: The Analytic Hierarchy Process, RWS Publications Pittsburgh.

Smart. A., and Harrison. A. (2003) Online reverse auctions and their role in buyer-supplier relationships. Journal of Purchasing \& Supply Management, 9, 257--268.

Smith. R. (1980) The contract net protocol. High-level communication and control in a distributed problem solver. IEEE Transactions on Computers 29(12), 1104--1113.

Telle O., Thierry C., and Bel., G. (2004) Aide à la coopération au sein d'une relation Donneur d'Ordres/Fournisseur dans le secteur aéronautique : Un outil de simulation. Journal Européen des Systèmes Automatisés, 38 (1-2), 7--36.

Toolea, T., and Donaldsonb, B. (2002) Relationship performance dimensions of buyer-supplier exchanges. European Journal of Purchasing \& Supply Management, 8, 197--207. 
Van Brussel. H., Wyns. J., Valckenears. P., Bongaerts. L., and Peeters. P. (1998) Reference architecture for holonic manufacturing systems: PROSA. Computers in Industry, 37 (3), 255--276.

Vargas, L.G. (1990) An Overview of the Analytic Hierarchy Process and its Applications. European Journal of Operational Research, 48 (1), 2--8.

Villa, A. (1998) Organizing a 'network of entreprises': an object-oriented design methodology. Computer Integrated Manufacturing Systems, 11 (4), 331--336.

Wedley, W.C. (1990) Combining Qualitative and Quantitative Factors - An Analytic Hierarchy Approach. Socio Economic Planning Sciences, 24 (1), 57--64.

Zacharewicz. G., Giambiasi. N., and Frydman. C. (2005b) GDEVS/HLA Environment: A Time Management Improvement. IMACS'2005 - the 17th IMACS World Congress on Scientific Computation, Applied Mathematics and Simulation, Paris, France.

Zacharewicz. G., Giambiasi. N., and Frydman. C. (2005a) Improving the DEVS/HLA Environment. DEVS Integrative M\&S Symposium, Part of the 2005 SCS Spring Simulation Multiconference, SpringSim'05, San Diego, California, USA.

Zeigler. B. (1976) Theory of modelling and simulation, Wiley \& Sons, New York.

Zeigler. B., Praehofer. H., and Kim. T. (2000) Theory of Modeling and Simulation, 2nd Edition, Academic Press, New York. 


\title{
APPENDIX 1. FORMALISM DEVS (Discret EVent system Specification).
}

\author{
(Ziegler, 1976), (Ziegler et al., 2000)
}

\section{Atomic DEVS Model:}

Formally, an atomic model $\mathrm{M}$ is specified by:

$\mathrm{M}=<\mathrm{X}, \mathrm{S}, \mathrm{Y}, \delta_{\mathrm{int}}, \delta_{\text {ext }}, \lambda$, ta $>$ : where :

$\mathbf{X}:\{(\mathrm{p}, \mathrm{v}) \mid \mathrm{p} \in$ input ports, $\mathrm{v} \in \mathrm{Xp}\}$ : the set of input ports through which external events are received

$\mathbf{Y}:\{(\mathrm{p}, \mathrm{v}) \mid \mathrm{p} \in$ output ports, $\mathrm{v} \in \mathrm{Yp}\}$ the set of output ports through which external events are sent

S: the set of the states .

$\boldsymbol{\delta}_{\text {int: }}$ internal transition function $: \mathrm{S} \rightarrow \mathrm{S}$. The model being in a state $\mathbf{s}$ at $\mathbf{t}_{\mathbf{i}}$, it will go in $\mathrm{s}^{\prime}$, $\mathrm{s}^{\prime}=\delta_{\text {int }}(\mathrm{s})$, if no external event occurs before $\mathbf{t}_{\mathbf{i}}+\operatorname{ta}(\mathrm{s})$.

$\boldsymbol{\delta}_{\text {ext }}$ : external transition function: $\mathrm{S} \rightarrow \mathrm{S}$. When an external event occurs, the model being in a state $\mathbf{s}$ during a time $\mathbf{e}$, it will goes in $\mathrm{s}^{\prime} . \mathrm{s}^{\prime}=\delta_{\mathrm{ext}}(\mathrm{s}, \mathrm{e}, \mathrm{x})$. At each change state $\mathbf{e}$ is reset to 0 . $\lambda$ : output function: $\mathrm{S} \rightarrow \mathrm{Y}$. This function is executed before the internal transition function. ta: the duration of a state if no external event occurs : $\mathbf{S} \rightarrow \mathbf{R}+$.

Q: set of states of a model: $\mathrm{Q}=\left\{(\mathrm{si}, \mathrm{e})\right.$ si $\left.\in \mathrm{S}, \mathrm{o}<\mathrm{e}<\mathrm{ta}\left(\mathrm{s}_{\mathrm{i}}\right)\right\}$.

e: is the elapsed time in the state $\mathrm{s}$.

The Information and Systems Science Laboratory (LSIS) has developped a graphic representation which allow simplifying the representation of the internal and external transition functions as well as the output function. 


\section{Insert Fig. A1 here}

\section{Coupled DEVS model:}

This universal formalism was extended in order to allow the association of coupled and atomic models in a hierarchical and modular manner.

A coupled DEVS model is defined by the following structure (Zeigler et al. 2000):

$\mathbf{M C}=<\mathrm{X}, \mathrm{Y}, \mathrm{D},\left\{\mathrm{M}_{\mathrm{d}} \mid \mathrm{d} \in \mathrm{D}\right\}, \mathrm{EIC}, \mathrm{EOC}, \mathrm{IC}>$. where:

X: input events set .

Y: output events set.

D: is a set of components names.

Md: DEVS model for each $d € D$.

EIC: external input coupling relation.

EOC: external output coupling relation

IC: internal coupling relation

Insert Fig. A2 here 


\section{LIST OF FIGURES AND TABLES}

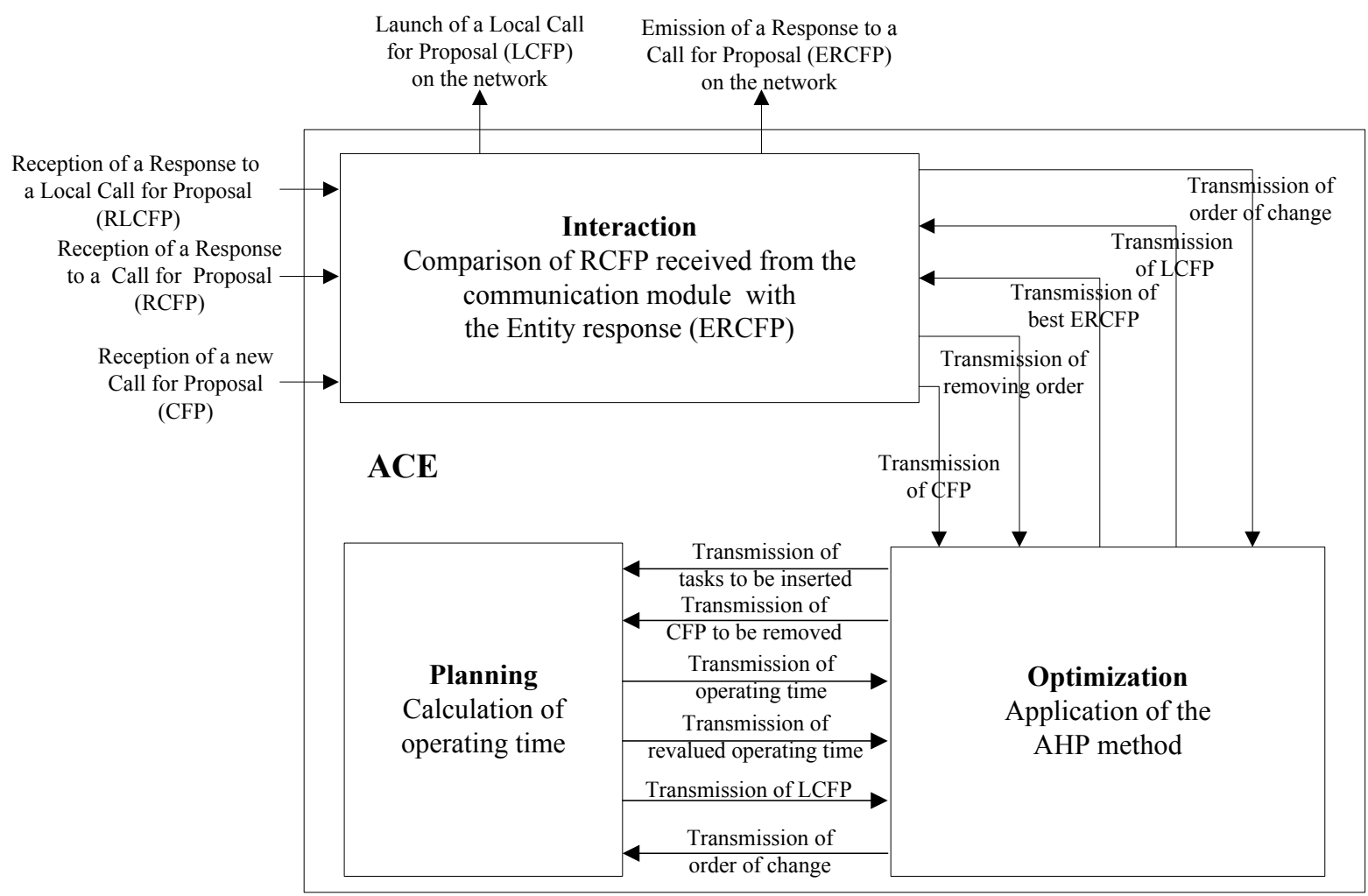

Fig. 1. Autonomous Control Entity incorporated into a supplier Resource Holon

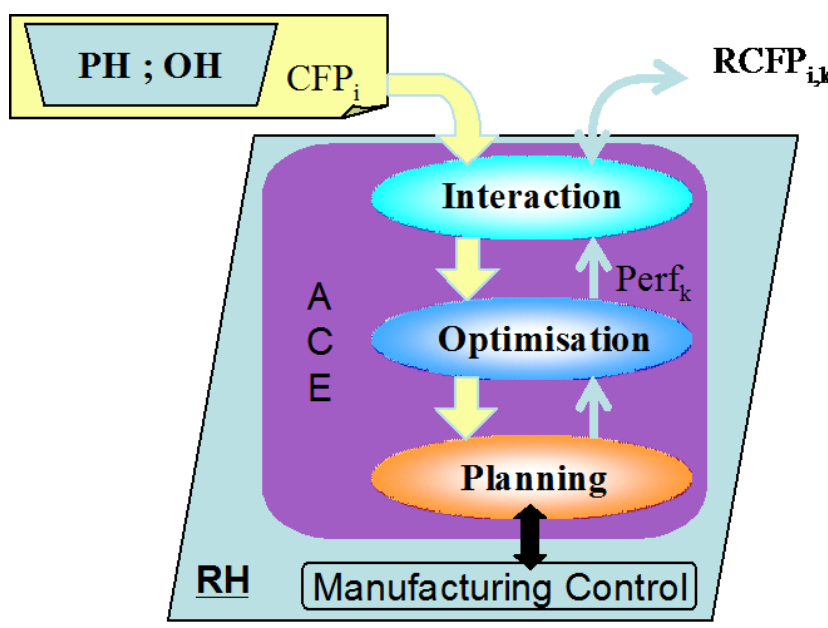

Fig. 2. Interaction among the basic holons - ACE 


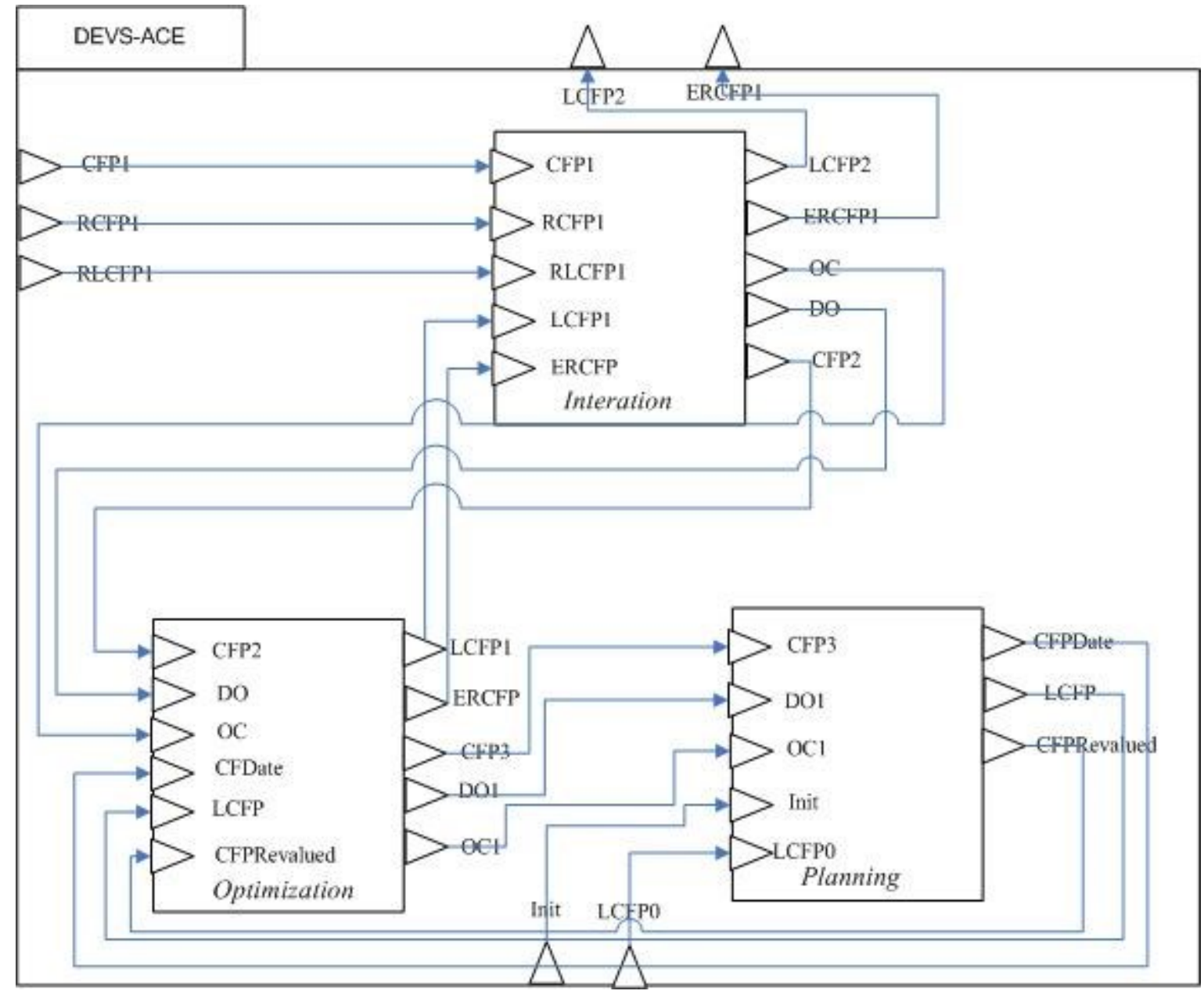

Fig. 3. DEVS-ACE Coupled Model 


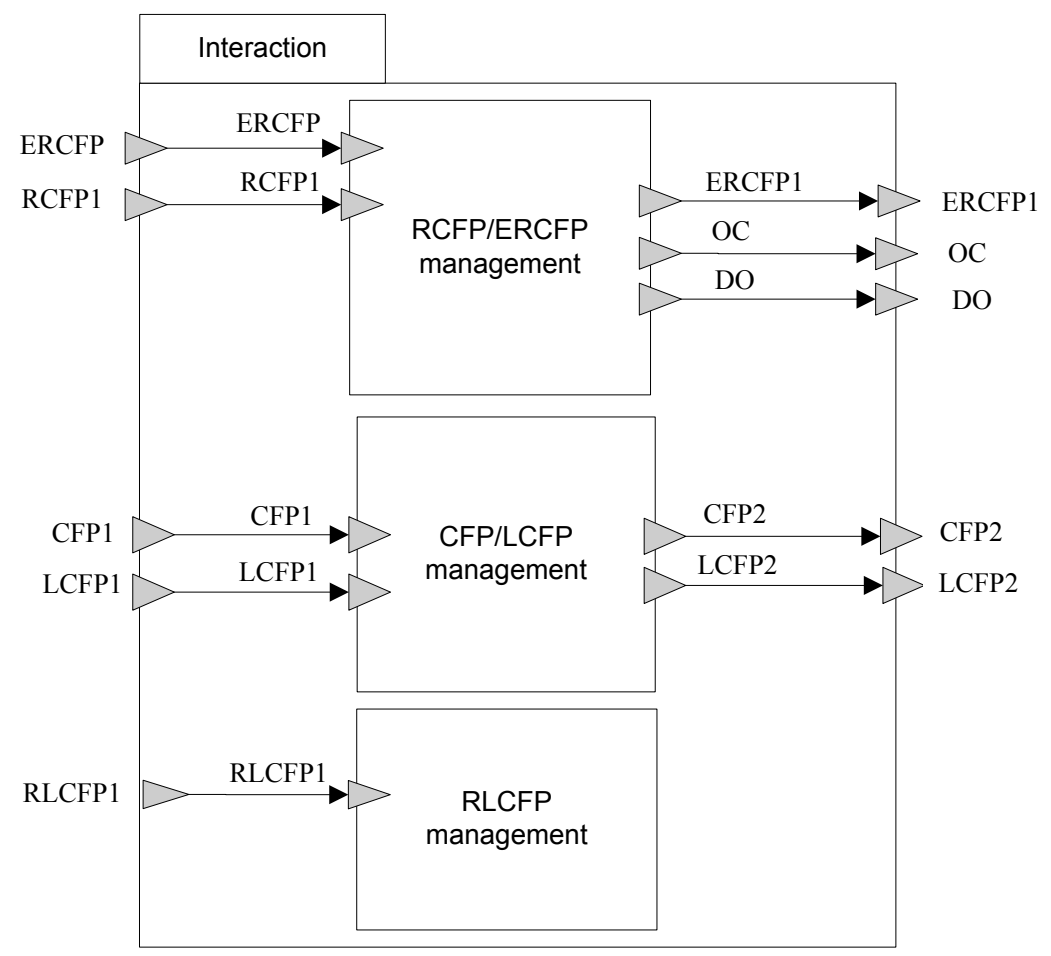

Fig. 4. Interaction Coupled Model

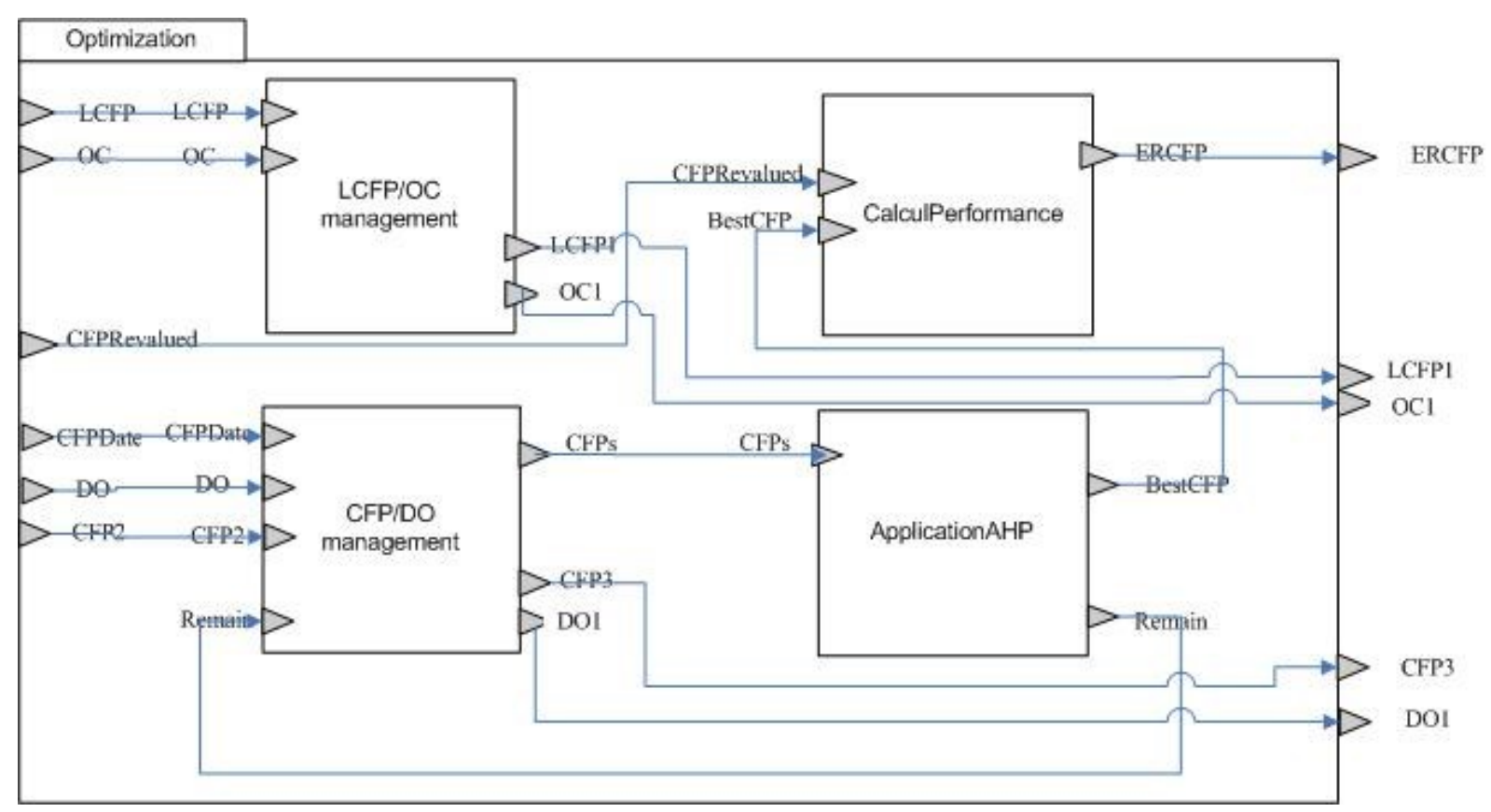

Fig. 5. Optimization Coupled Model 


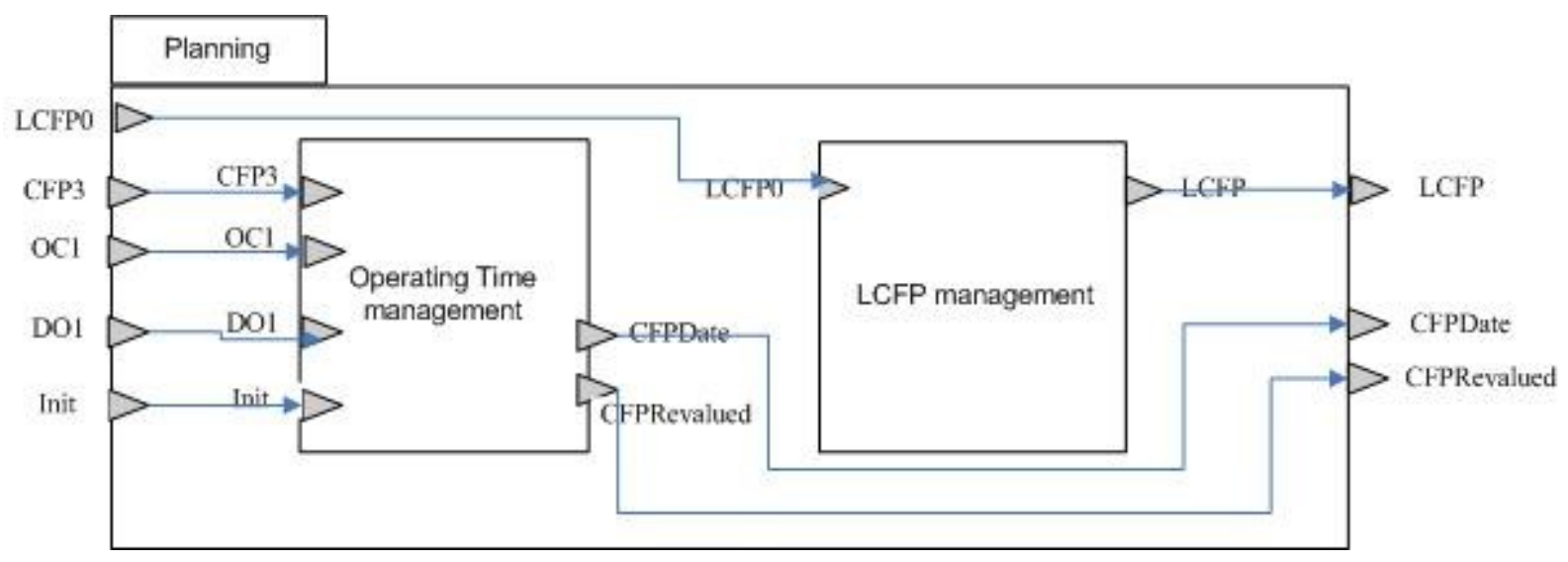

Fig. 6. Planning Coupled Model

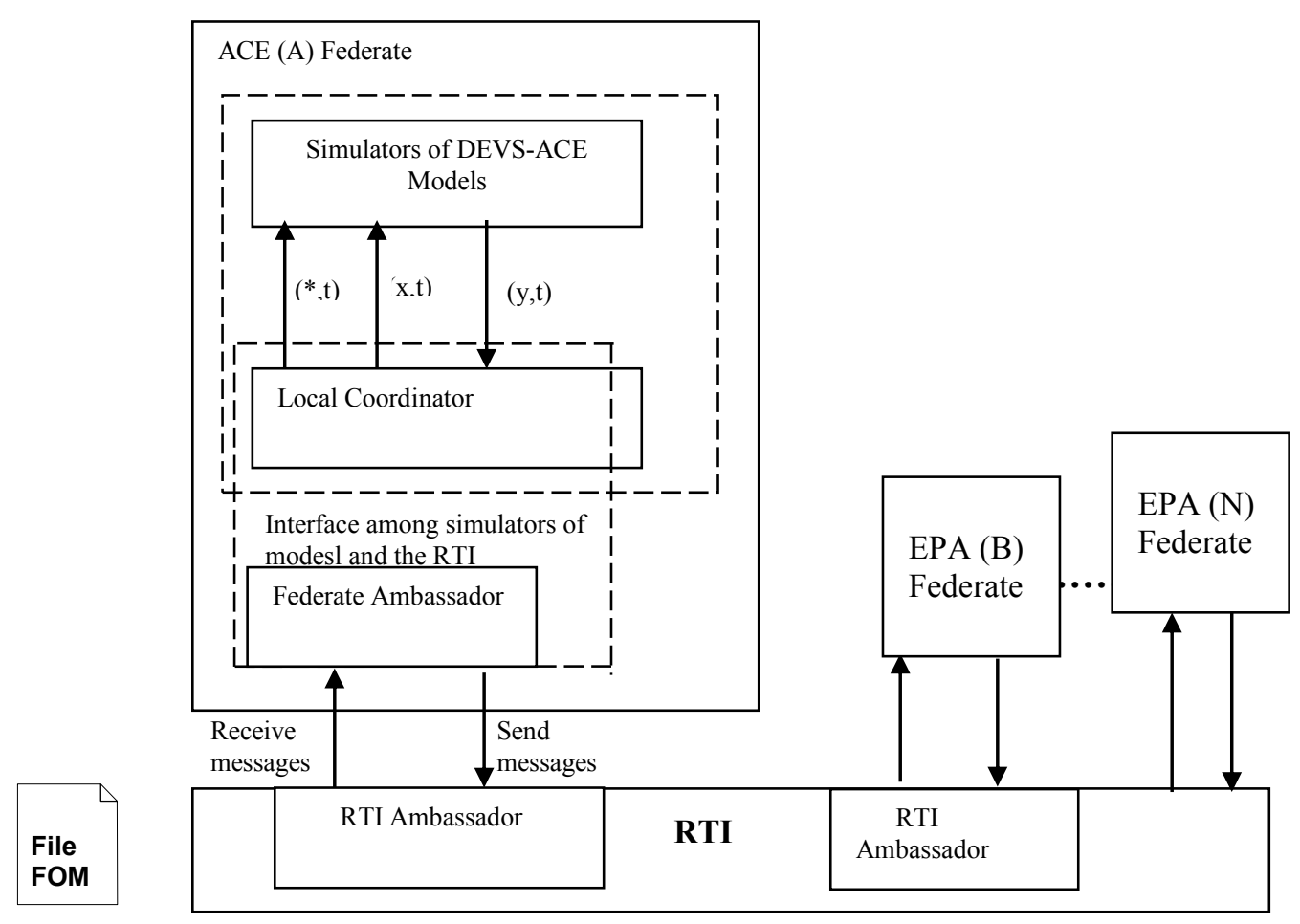

Fig. 7. Relations among the simulation components 


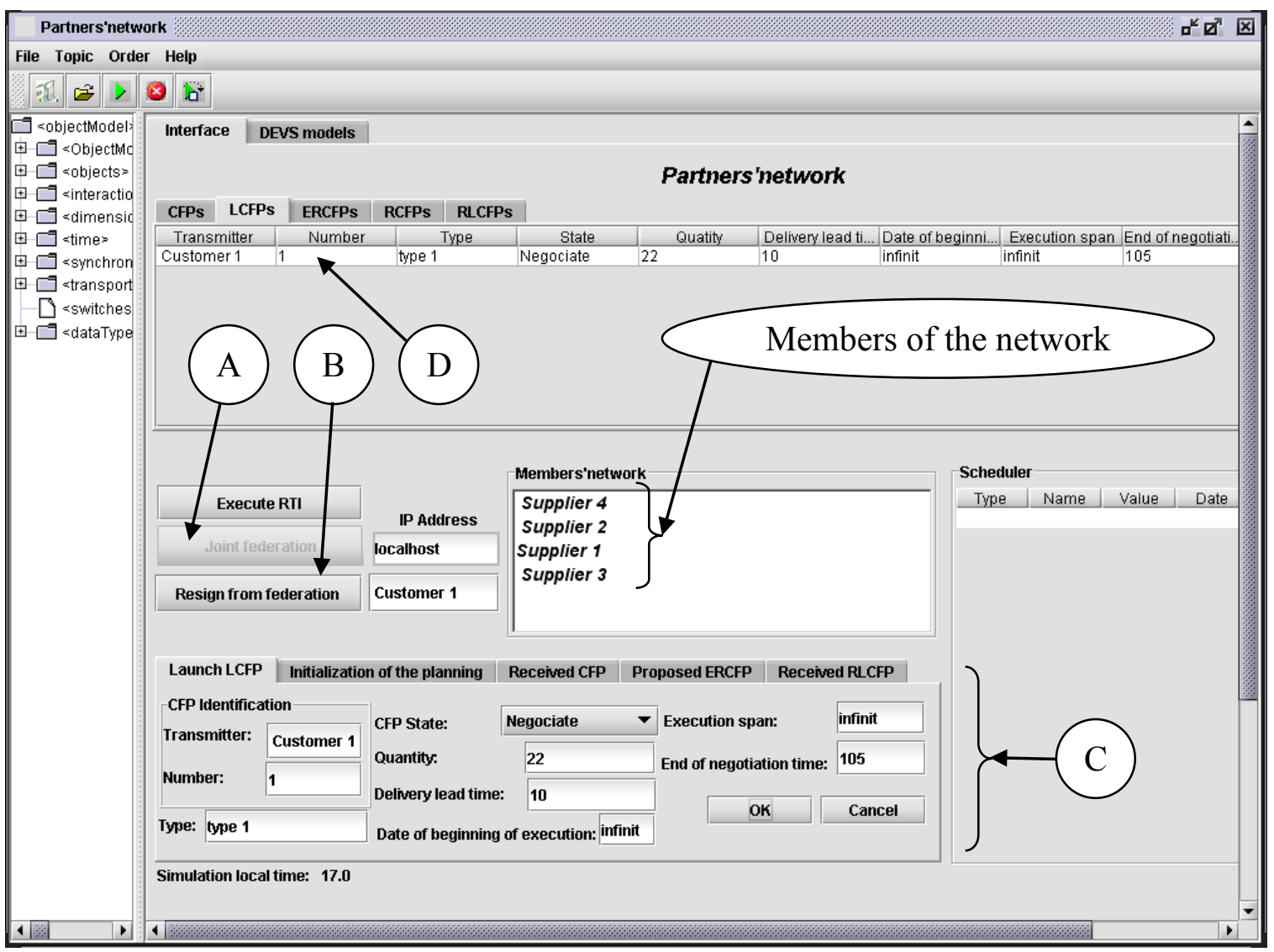

Fig. 8. ACE federate interface 


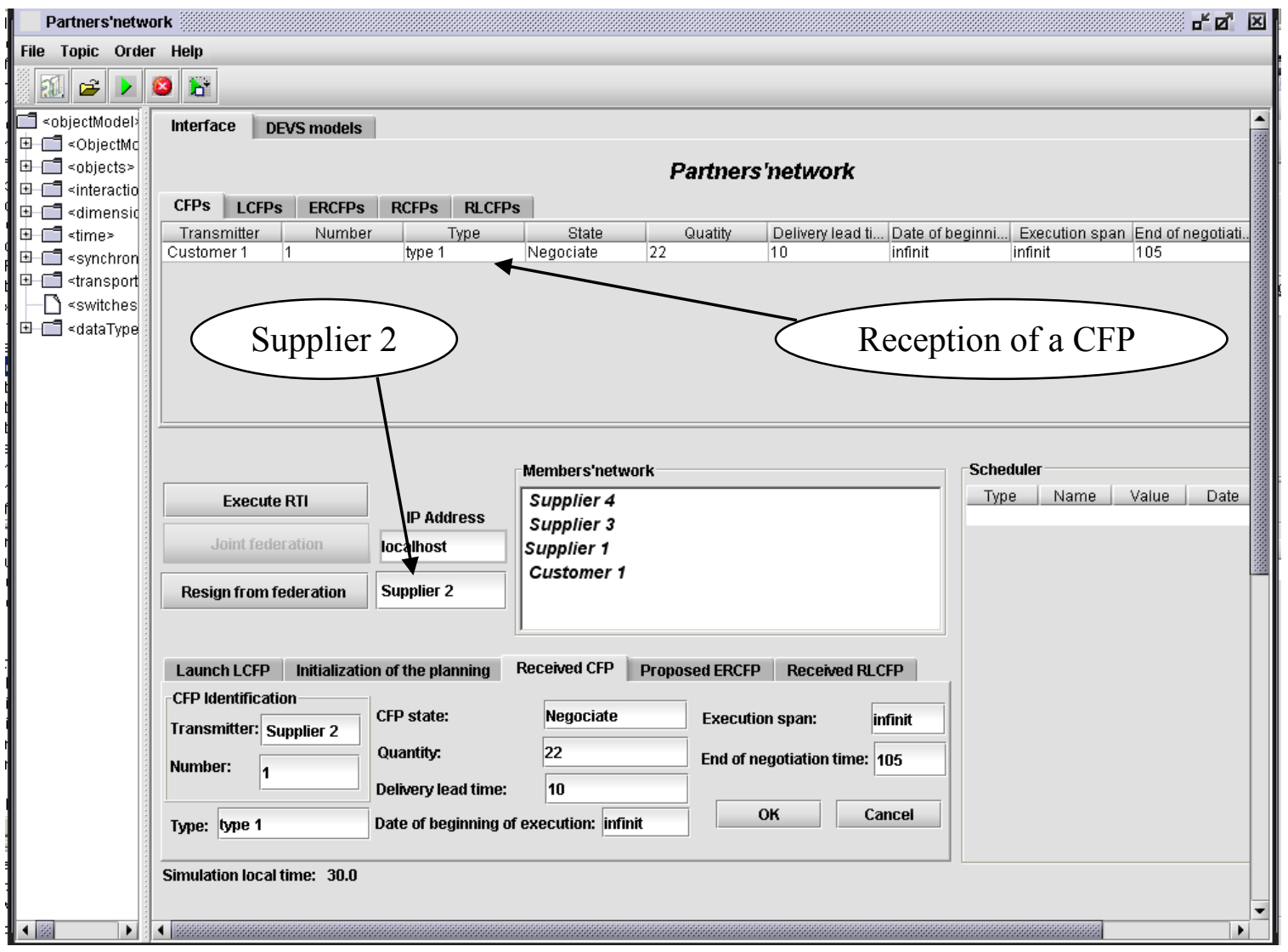

Fig. 9. Reception of a CFP by a Supplier (Supplier 2) 


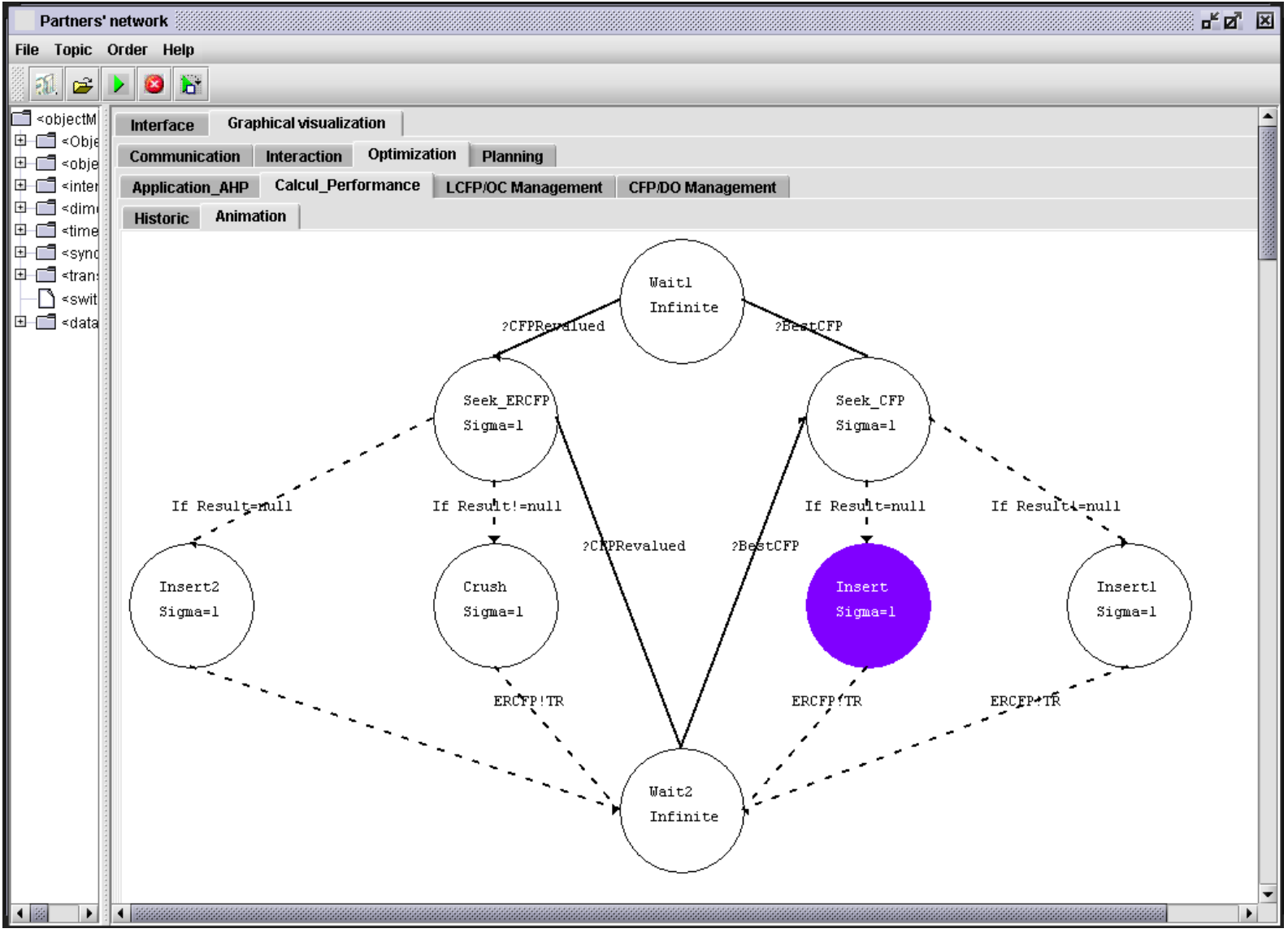

Fig. 10. 'Calcul_Performance' sub model of a supplier 


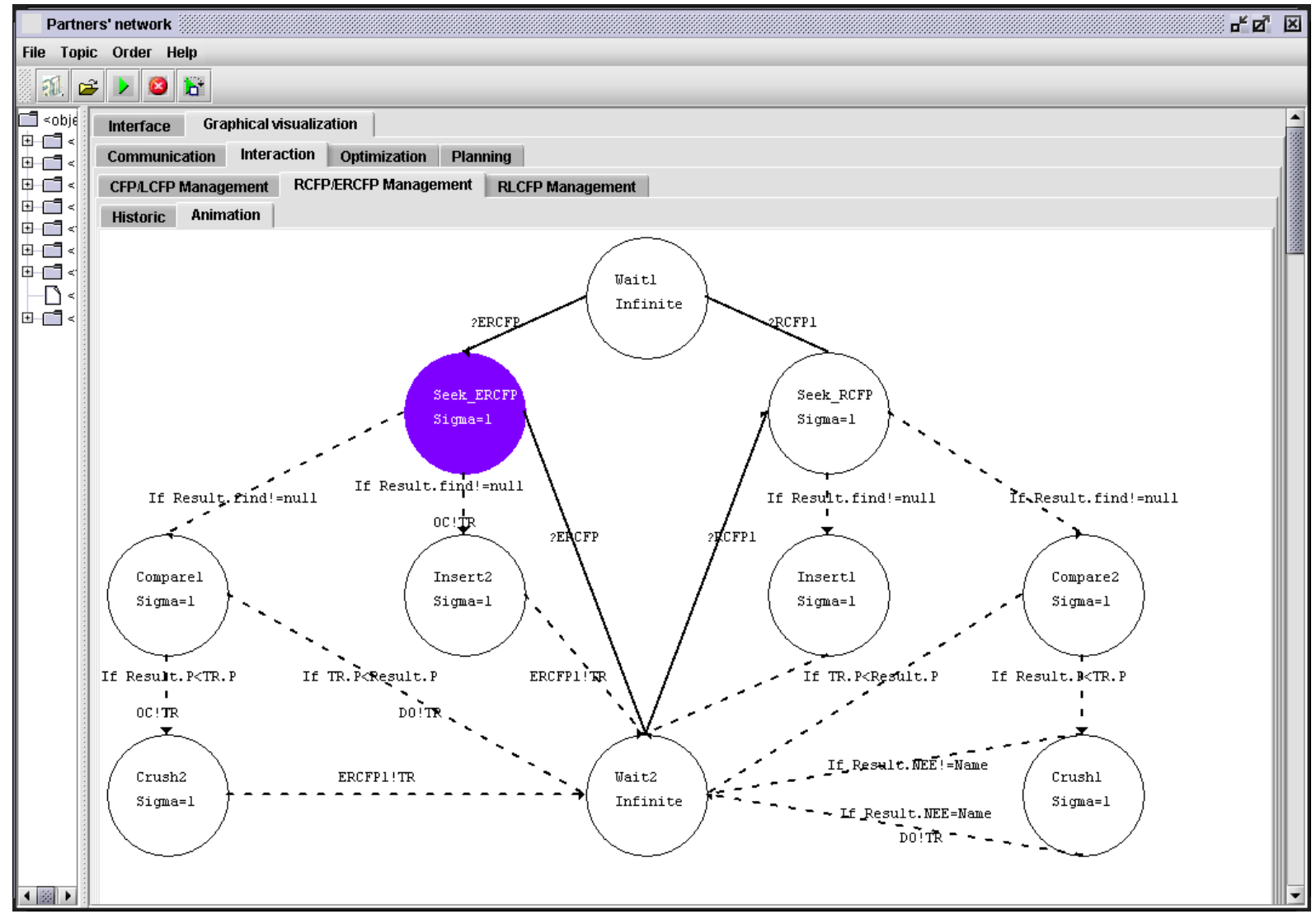

Fig. 11. 'RCFP/ERCFP Management' Interaction sub model of a supplier 


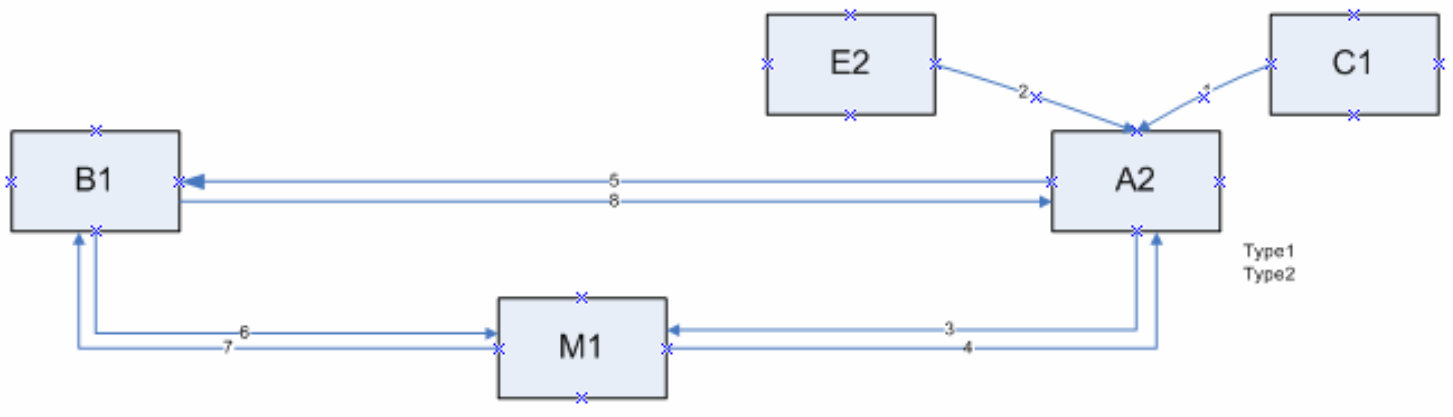

Fig. 12. Sub contracting levels

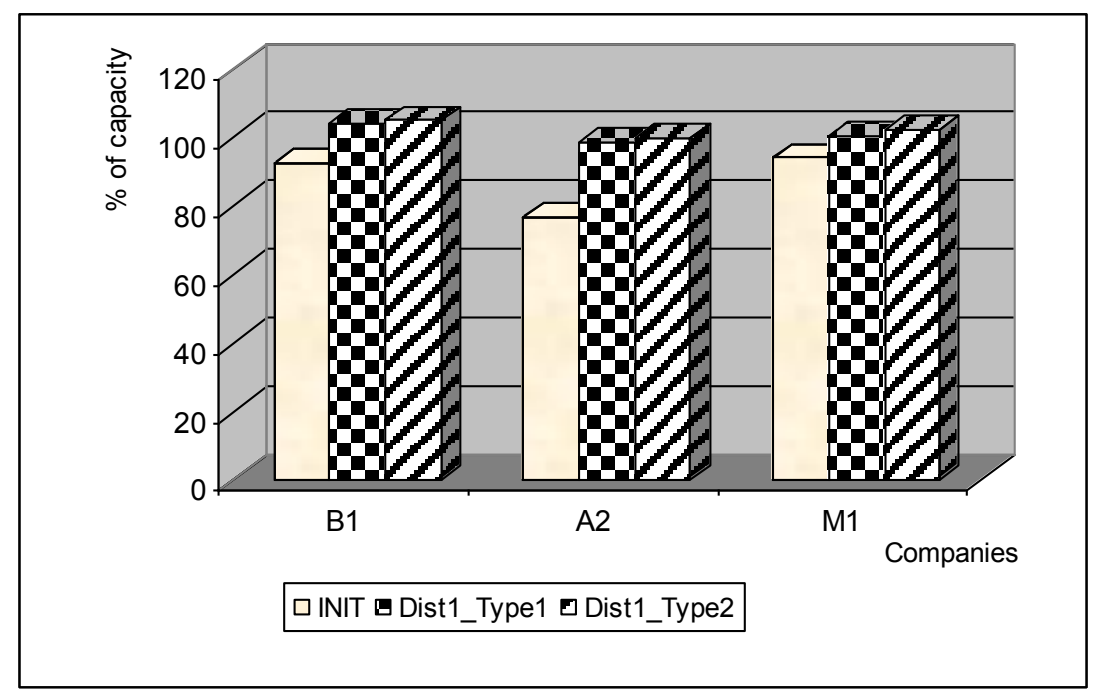

Fig. 13. Load of A2, B1 and M1 companies 


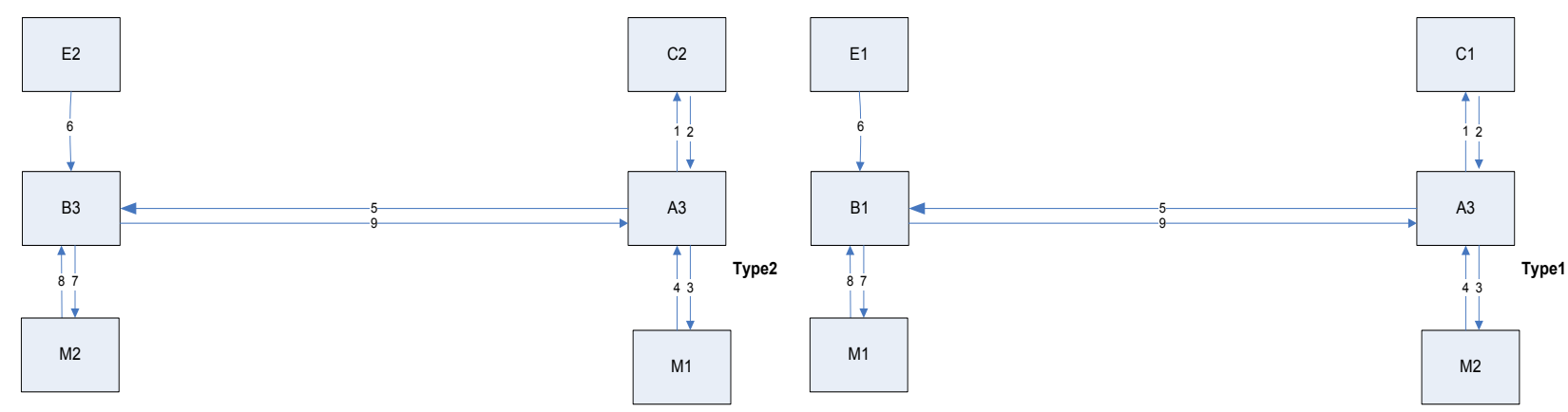

Fig. 14. Representation of the two types of product PF1 new flows

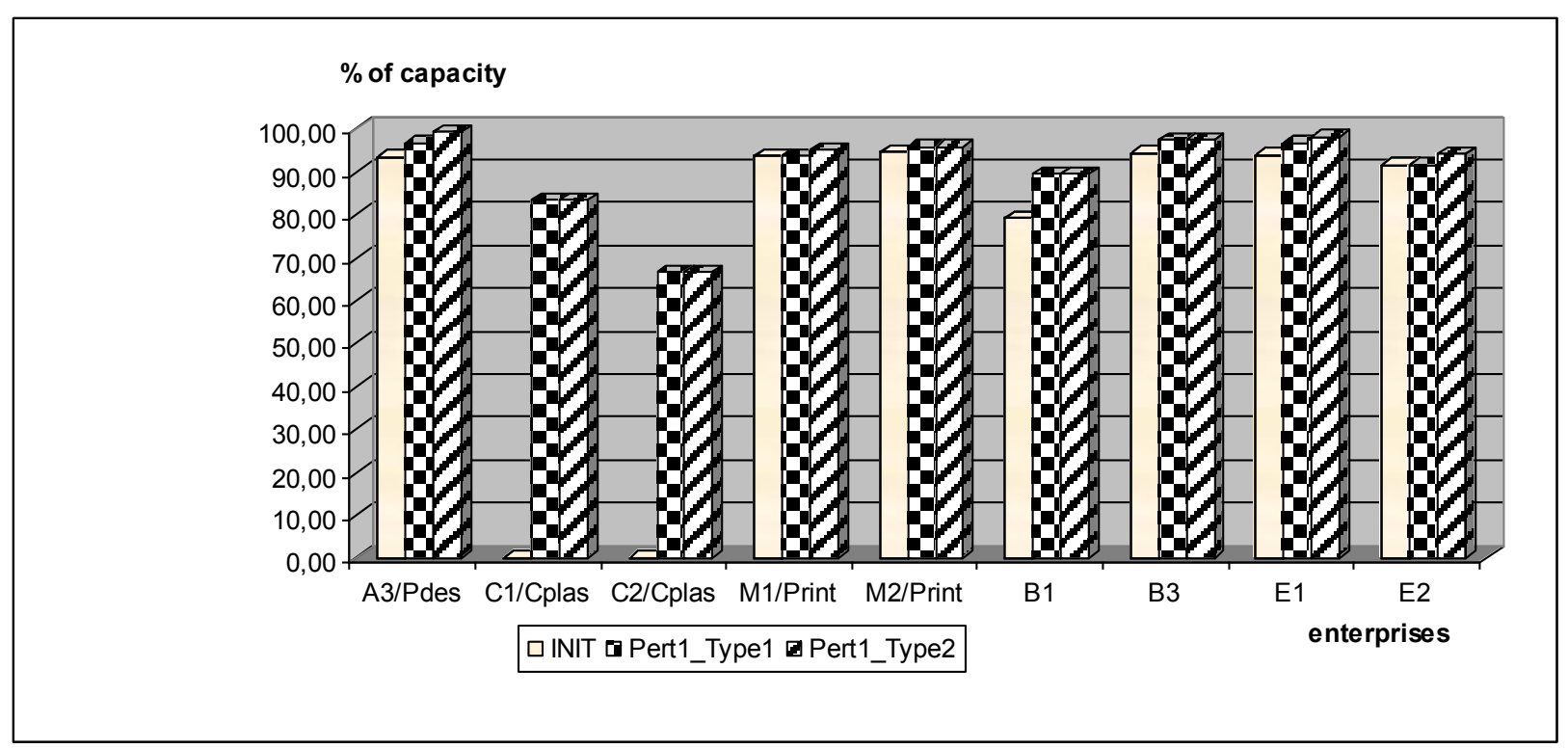

Fig. 15. Load smoothings of A3, C1, C2, M1, M2, B1, B3, E1 and E2 companies 


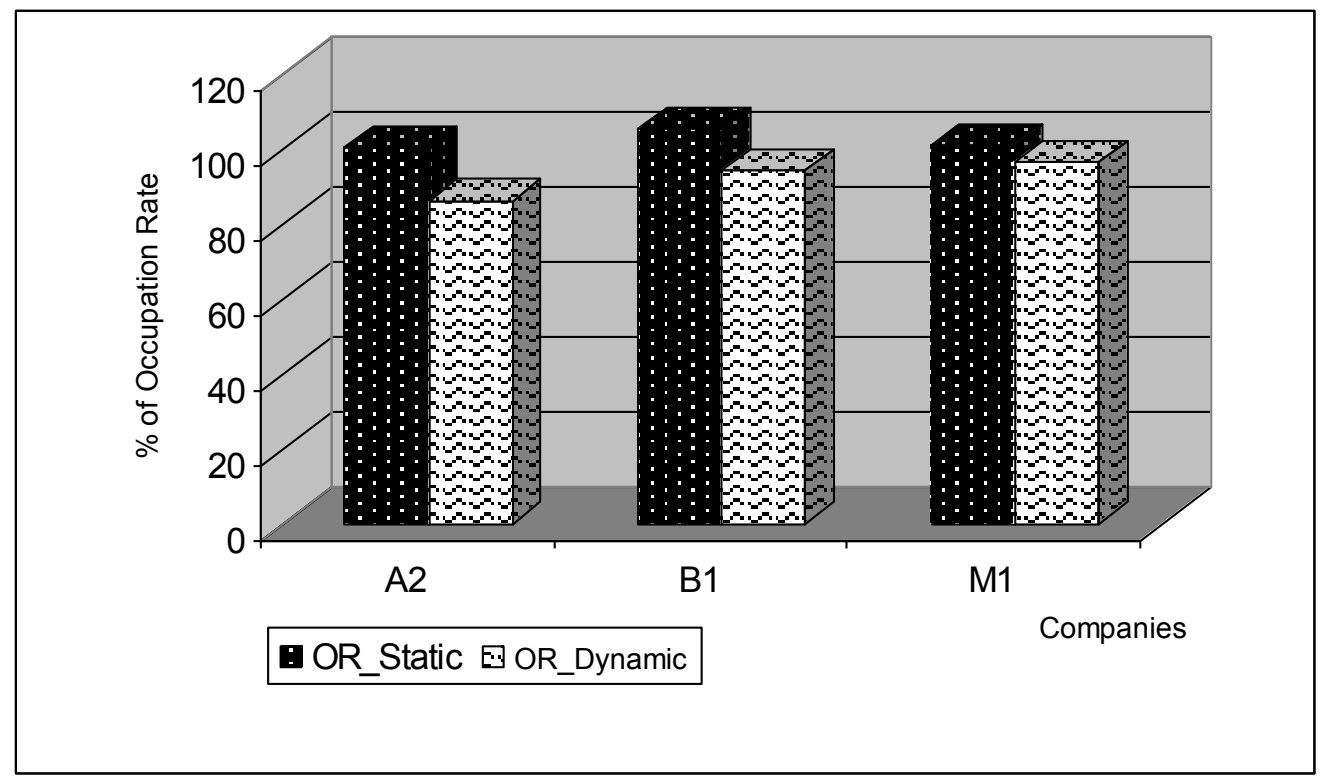

Fig. 16. Occupation rate of A2, B1 and M1 companies

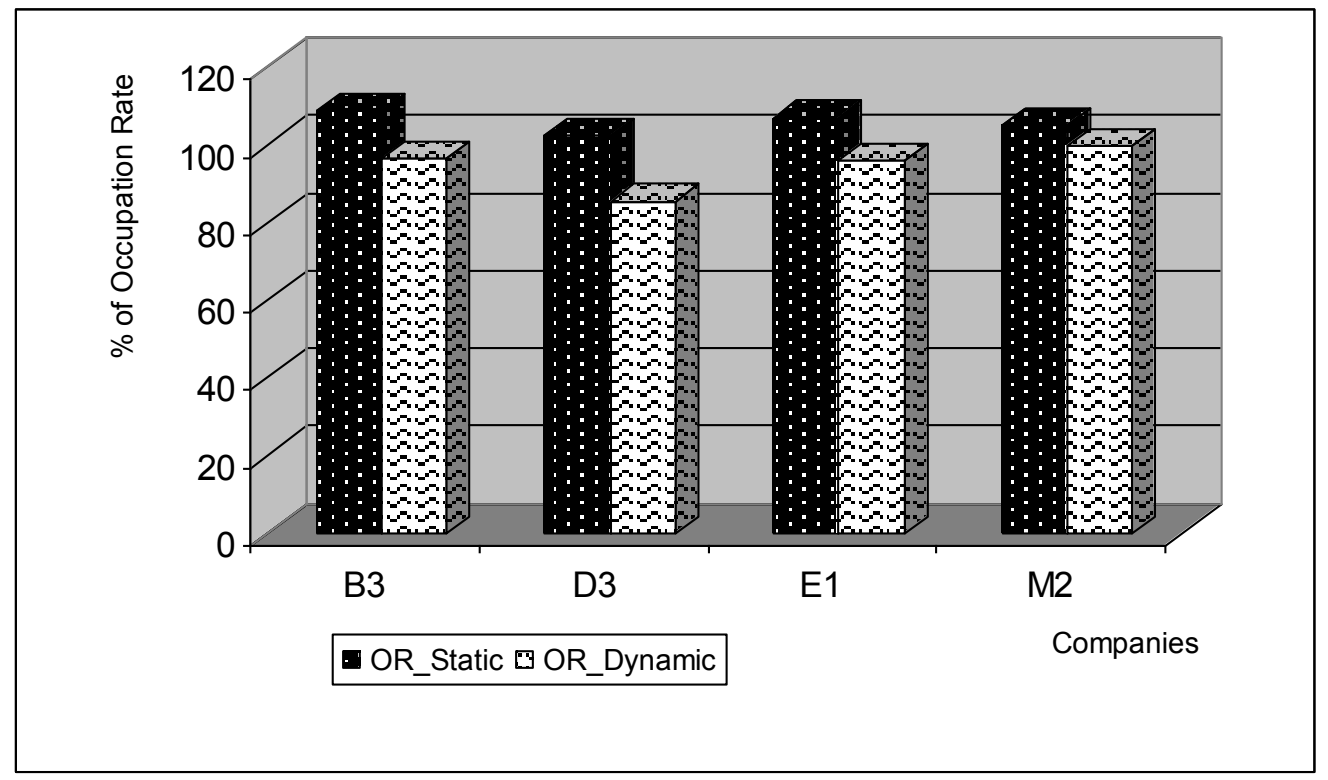

Fig. 17. Occupation rate of B3, D3, E1 and M2 companies 


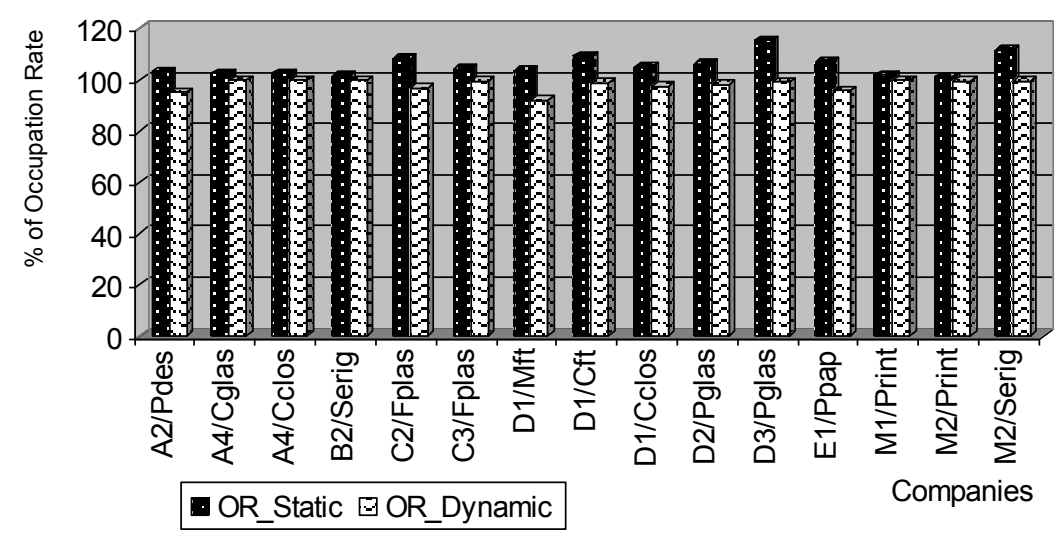

Fig. 18. Occupation rate of A2, A4, B2, C2, C3, D1, D2, D3, E1, M1 and M2 companies

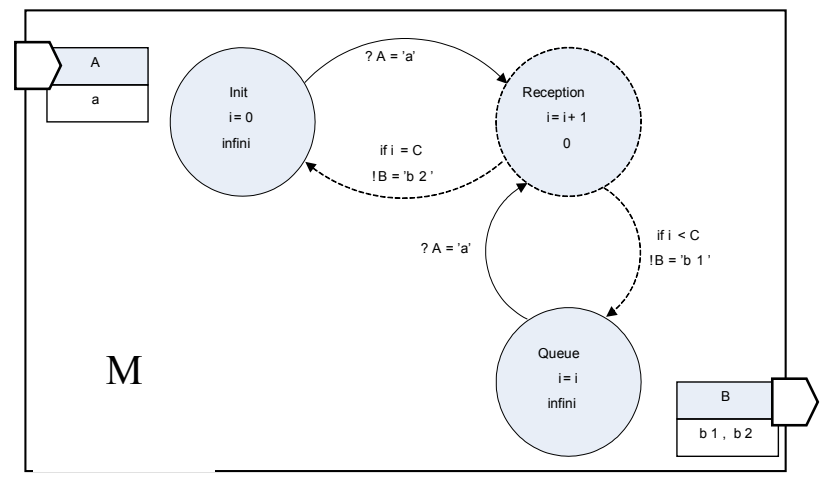

Fig. A1. DEVS atomic model

Legend:

- A state is represented by a circle, continuous for a stable, dotted for a fleeting state. This circle contains the name of the state, the operations on variables and the state lifespan $\left(\mathrm{t}_{\mathrm{a}}\right)$.

- (A) is an input port, which can receive the value (a).

- (B) is an exit port, which can take the values (b1) \& (b2), according to the following syntax $(! \mathrm{B}=$ 'bx').

- A dotted line shows an internal transition.

A continuous line represents an external transition: a port $(\mathrm{X})$ takes the value $(\mathrm{y})$, according to the following $\operatorname{syntax}(? \mathrm{X}=$ 'y').

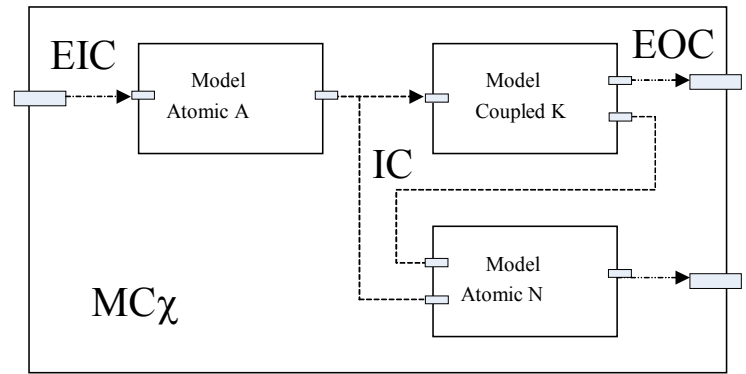

Fig. A2. Coupled DEVS model 
Table 1. Summary table of the criteria and indicators

\begin{tabular}{llll}
\hline & Indicator & \multicolumn{1}{c}{ Description } & Nature \\
Lead time criterion C1 & I11 & Production time & Quantitative \\
& I12 & Delivery time & Quantitative \\
Cost criterion C2 & I21 & Cost of order & Quantitative \\
Quality criterion C3 & I22 & Cost of order delivery & Quantitative \\
& I31 & Rate of conformity & Quantitative \\
& I32 & Respect of a referential & Qualitative \\
Reliability criterion C4 & I33 & Rate of customer satisfaction & Quantitative \\
& I41 & Conformity in quantity of the orders & Quantitative \\
& I42 & Respect for delivery times & Quantitative \\
& I51 & Allowance of differed payment & Qualitative \\
& I52 & Degree of privilege & Qualitative \\
\hline
\end{tabular}


Table 2. Initial dimensioning of the companies

\begin{tabular}{|c|c|c|c|c|}
\hline Companies & Activities & $\begin{array}{l}\text { Activities' } \\
\text { Codes }\end{array}$ & $\begin{array}{c}\text { Load / } \\
\text { Activity }\end{array}$ & $\begin{array}{l}\text { Capacity Max } \\
\text { / Activity }\end{array}$ \\
\hline \multirow{6}{*}{ A1 } & Cosmetic product design and production & Pdes & 462,50 & 490 \\
\hline & Plastic product fabrication & Fplas & 340,28 & 350 \\
\hline & Product conditioning in glass containers & Cglas & 9,72 & 15 \\
\hline & Container closing & Cclos & 29,17 & 35 \\
\hline & Labelling & Label & 69,44 & 75 \\
\hline & Products assembling & Ass & 138,89 & 145 \\
\hline \multirow[t]{5}{*}{$\mathrm{A} 2$} & Cosmetic product design and production & PDes & 63,33 & 70 \\
\hline & Plastic conditioning for products & Cplas & 30,00 & 34 \\
\hline & Container closing & Cclos & & 5 \\
\hline & Labelling & Label & 15,00 & 16 \\
\hline & Products assembling & Ass & & 5 \\
\hline A3 & Cosmetic product design and production & Pdes & 243,33 & 260 \\
\hline \multirow[t]{5}{*}{ A4 } & Cosmetic product design and production & Pdes & 69,44 & 80 \\
\hline & Product conditioning in glass containers & Cglas & 41,67 & 45 \\
\hline & Container closing & Cclos & 41,67 & 45 \\
\hline & Labelling & Label & & 5 \\
\hline & Products assembling & Ass & 26,67 & 30 \\
\hline \multirow[t]{2}{*}{ B1 } & Paper production and transformation & Ppap & 158,33 & 165 \\
\hline & Paper packaging & Ppap & 31,67 & 40 \\
\hline \multirow[t]{3}{*}{ B2 } & Paper production and transformation & Ppap & 256,94 & 280 \\
\hline & Paper packaging & Ppap & 48,61 & 55 \\
\hline & Printing & Print & 191,67 & 195 \\
\hline B3 & Paper packaging & Ppap & 103,89 & 110 \\
\hline \multirow[t]{5}{*}{$\mathrm{C} 1$} & Plastic product fabrication & Fplas & 51,67 & 55 \\
\hline & Plastic conditioning for products & Cplas & & 5 \\
\hline & Container closing & Cclos & & 5 \\
\hline & Labelling & Label & & 5 \\
\hline & Products assembling & Ass & & 5 \\
\hline \multirow[t]{5}{*}{$\mathrm{C} 2$} & Plastic product fabrication & Fplas & 162,22 & 170 \\
\hline & Plastic conditioning for products & Cplas & & 5 \\
\hline & Container closing & Cclos & & 5 \\
\hline & Labelling & Label & & 5 \\
\hline & Products assembling & Ass & & 5 \\
\hline \multirow[t]{5}{*}{$\mathrm{C} 3$} & Plastic product fabrication & Fplas & 211,94 & 220 \\
\hline & Plastic conditioning for products & Cplas & & 5 \\
\hline & Container closing & Cclos & & 5 \\
\hline & Labelling & Label & 11,11 & 15 \\
\hline & Products assembling & Ass & 44,44 & 50 \\
\hline \multirow[t]{7}{*}{ D1 } & Flexible tube manufacturing & Mft & 37,78 & 44 \\
\hline & Flexible tube conditioning & $\mathrm{Cft}$ & 14,44 & 16 \\
\hline & Container closing & Cclos & 64,17 & 70 \\
\hline & Labelling & Label & & 5 \\
\hline & Production Conditionning in glass containers & Fver & 83,33 & 90 \\
\hline & Liquid conditioning in glass containers & Cgla & 6,94 & 10 \\
\hline & Products assembling & Ass & & 5 \\
\hline \multirow[t]{4}{*}{ D2 } & Flexible tube manufacturing & Mft & 25,00 & 30 \\
\hline & Flexible tube conditioning & $\mathrm{Cft}$ & 8,33 & 10 \\
\hline & Container closing & Cclos & 16,67 & 20 \\
\hline & Glass packaging and production & Pgla & 95,28 & 100 \\
\hline
\end{tabular}




\begin{tabular}{ccccc}
\hline & Liquid conditioning in glass containers & Cgla & & 5 \\
Products assembling & Ass & & 5 \\
D3 & Flexible tube manufacturing & Mft & & 5 \\
& Flexible tube conditioning & Cft & & 5 \\
& Container closing & Cclos & 22,22 & 30 \\
& Labelling & Label & & 5 \\
& Glass packaging and production & Pgla & 60,56 & 70 \\
& Liquid conditioning in glass containers & Cgla & 11,11 & 15 \\
E1 & Products assembling & Ass & 44,44 & 50 \\
E2 & Paper production and transformation (cardboard, labels...) & Ppap & 281,94 & 300 \\
M1 & Paper production and transformation (cardboard, labels...) & Ppap & 119,17 & 130 \\
& Printing & Print & 134,17 & 138 \\
M2 & Serigraphy & Serig & 100,28 & 112 \\
& Printing & Print & 234,44 & 250 \\
& Serigraphy & Serig & 129,72 & 135 \\
\hline
\end{tabular}

